\title{
Competição, Colusão e Antitruste: estimação da conduta competitiva de companhias aéreas
}

\author{
Frederico Araujo Turolla*, Débora Lovadine ${ }^{\dagger}$, Alessandro Vinícius \\ Marques de Oliveira ${ }^{\ddagger}$
}

Sumário: 1. Introdução; 2. Desregulamentação e Antitruste no Transporte Aéreo Nacional: Breve Relato; 3. Modelagem da Conduta e Investigação de Comportamento Colusivo; 4. Estimação da Conduta das Companhias Aéreas; 5. Conclusões; A. A Técnica de Bootstrapping; B. Lucratividade no Mercado (Dados Contábeis).

Palavras-chave: Antitruste; poder de mercado; conduta; transporte aéreo.

Códigos JEL: L13; L50; L93.

A política antitruste tem sido cada vez mais considerada como relevante mecanismo de promoção do bem-estar econômico em mercados oligopolísticos recentemente liberalizados. O objetivo do presente trabalho é o de promover, por meio de modelo estrutural empírico, uma investigação de um suposto comportamento de coordenação de preços por parte das companhias aéreas na Ponte Aérea Rio de Janeiro - São Paulo. A metodologia utiliza um parâmetro de conduta, relacionado com a abordagem da Nova Organização Industrial Empírica, e assim concentra-se nos efeitos das práticas colusivas, tendo por isso a vantagem de não depender de evidências de conluio, como a existência de comunicação prévia entre as empresas envolvidas. Os resultados obtidos com a modelagem empírica utilizando-se um estimador em duas etapas (Two-Step Estimator) indicam que não há bases para se rejeitar a hipótese de que as empresas mantiveram uma conduta não-cooperativa no mercado, ao contrário do que recentemente decidiram as autoridades de defesa da concorrência brasileiras.

Antitrust policy has been increasingly considered as relevant mechanism of economic welfare promotion in recently liberalized oligopolistic markets. The

\footnotetext{
* Fundação Getúlio Vargas, FGV/SP e Escola Superior de Propaganda e Marketing/ESPM.

${ }^{\dagger}$ Núcleo de Estudos em Competição e Regulação do Transporte Aéreo - NECTAR.

¥Núcleo de Estudos em Competição e Regulação do Transporte Aéreo - NECTAR. Instituto Tecnológico de Aeronáutica. Endereço para correspondência: Praça Marechal Eduardo Gomes, 50 - Vila das Acácias - CEP 12228-900 - São José dos Campos - SP.
} 
purpose of this paper is to develop a structural model, in order to investigate alleged price coordination by the airlines on the air shuttle route Rio de Janeiro - São Paulo. By making use of a conduct parameter, based on the New Empirical Industrial Organization approach, it was possible to focus on the effects of the formation of an alleged cartel instead of relying on evidence of collusion such as previous communication between the involved companies. Results achieved using a Two-Step Estimator indicated no basis for rejecting the hypothesis that firms kept non-cooperative conduct in the market, contrary to recent decision by the Brazilian antitrust authorities.

\section{INTRODUÇÃO}

O crescente uso de instrumentos de defesa da concorrência em todo o mundo coloca novos desafios teóricos e empíricos para a Teoria Econômica. No Brasil, a política antitruste só começou a ser utilizada de forma mais efetiva a partir da estabilização de preços propiciada pelo Plano Real, em 1994. A partir de então, o País passou a dispor de um aparato regulatório mais efetivo com vistas à execução das políticas de controle de condutas e de estruturas de mercado. Com o novo arcabouço, que substituiu o controle e a supervisão direta de preços, o ambiente de concorrência passou a contar com as políticas de defesa da concorrência como instrumentos importantes de promoção do bem-estar econômico, tanto em mercados liberalizados ou naturalmente isentos de regulação, quanto naqueles sujeitos à desregulamentação econômica parcial.

O presente trabalho visa desenvolver um exercício de investigação antitruste sobre uma conduta verificada em 1999 na indústria do transporte aéreo brasileiro, quando as quatro companhias que operavam a Ponte Aérea Rio de Janeiro - São Paulo aumentaram seus preços no mesmo dia, em um mesmo percentual - dez por cento. A conduta foi objeto de processo aberto pela Secretaria de Direito Econômico (SDE) do Ministério da Justiça em 2000, sob a alegação de conduta "combinada e uniforme" (Secretaria de Acompanhamento Econômico, 2001). O processo resultou em condenação das empresas com aplicação de multa, pela prática de infração da ordem econômica.

Para realizar a tarefa de averiguação se a conduta observada realmente representou, do ponto de vista econômico, uma efetiva coordenação, foi utilizada a abordagem baseada nos chamados "Modelos de Parâmetros de Conduta”, da Nova Organização Industrial Empírica, NOIE - cf. GEROSKI (1988), e BRESNAHAN (1989) para uma resenha, e GENESOVE e MULLIN (1998) para uma discussão mais recente. A idéia principal da metodologia visa a estimação de um sistema de equações de demanda e oferta, onde se possa mensurar um parâmetro que permita a inferência sobre a conduta (as "variações conjeturais") das empresas no mercado: se não-cooperativa (competitiva) ou se cooperativa (colusiva e com racionalidade de cartel). A análise visa contribuir com a literatura no sentido de estimular a aplicação desses métodos na apuração de infrações à ordem econômica.

O trabalho será conduzido por meio dos seguintes passos: na Seção 2, será feito um breve relato da Política de Flexibilização e do antitruste no transporte aéreo nacional; na Seção 3, será promovida a investigação da conduta no mercado da Ponte Aérea, com discussão dos fatos ocorridos e argumentos utilizados na abertura do processo, o estudo do mercado relevante, e a construção da modelagem da conduta; na Seção 4, tem-se o desenvolvimento do modelo empírico equivalente, bem como descrição dos dados, estimação, apresentação dos resultados, seguidos de inferências sobre o exercício de poder de mercado na ligação; ao final, as conclusões serão apresentadas. 


\section{DESREGULAMENTAÇÃO E ANTITRUSTE NO TRANSPORTE AÉREO NACIONAL: BREVE RELATO}

\subsection{A Política de Flexibilização e sua Redefinição}

O processo de liberalização do transporte aéreo brasileiro passa por um momento de transição. Iniciado nos anos 1990, quando foi inserido no contexto do então Programa Federal de Desregulamentação (Decreto n-99.179), esse conjunto de medidas chamado de "Política de Flexibilização do Transporte Aéreo" passou por três rodadas liberalizadoras (OLIVEIRA, 2005).

Na Primeira Rodada de Liberalização, a partir de 1992 (Portaria no 075/GM5, de 6 de fevereiro), oficializou-se o fim dos monopólios das companhias aéreas regionais, constituídos, desde 1976, pelo Sistema Integrado de Transporte Aéreo Regional (SITAR); apenas as chamadas "Linhas Aéreas Especiais" representaram exceções ao novo modelo. Na prática, rompia-se com um arcabouço montado no período mais típico da regulação do setor, cuja política era a de permitir a operação apenas de quatro companhias aéreas nacionais e cinco regionais. Tem-se, portanto, que o estímulo à entrada de novas operadoras no mercado passou a ser a política característica dessa fase, o que levou a uma onda de novas pequenas companhias aéreas entrantes.

A Primeira Rodada foi marcada ainda pela afirmação do instrumento da "banda tarifária", que havia sido introduzido em 1989. A autoridade aeronáutica definia preços de referências e limites superior e inferior de $-50 \%$ a $+32 \%$, de forma que a competição em preços passou a ser vista como "saudável" para o mercado, sendo também estimulada.

No final da década de 1990, o governo decidiu promover um conjunto adicional de medidas (Portarias do DAC, números 986/DGAC, de 18 de dezembro de 1997, e 05/GM5, de 9 janeiro de 1998), como forma de acelerar a trajetória rumo à plena desregulamentação do setor. Desta forma, dois instrumentos regulatórios fundamentais foram removidos: as "bandas tarifárias" e a exclusividade de operação das Linhas Aéreas Especiais pelas companhias regionais. Isto alavancou o que se pode chamar de $\mathrm{Se}$ gunda Rodada de Liberalização, que teve como conseqüência uma atividade de interação estratégica entre as companhias aéreas como há décadas não se via na indústria, com intensa competição em preços e freqüências. ${ }^{2}$

Importante mencionar que, durante a Segunda Rodada, a autoridade aeronáutica (DAC) encontrou barreiras relevantes no sentido de efetivar, já naquele momento, a total liberalização em preços. Isso aconteceu sobretudo porque havia entraves legais fundamentados na legislação do Plano Real, que conferia ao Ministério da Fazenda o poder de autorizar reajustes de preços. Esse fato, aliado ao choque de custos causado pela mudança de regime cambial em janeiro de 1999, acarretou pressão ascendente de preço, cujo repasse, ao não ser plenamente permitido, suscitou dúvidas quanto a real efetividade das medidas liberalizantes. Naquele momento começou a se desenhar um estado geral de crise financeira no setor, relacionado à dívida das empresas, a instabilidade cambial e ao próprio crescimento da economia que se desacelerou no biênio 1998/99. Este quadro produziu as primeiras críticas ao processo de desregulamentação até então empreendido.

Pode-se argumentar, como fazem VISCUSI et alii (1995), que, em setores com regulação de entrada e preço, o papel da política antitruste tende a ser limitado. Porém, já nesta Segunda Rodada de Liberalização aparecem elementos que possibilitam um maior papel para a defesa da concorrência, mesmo com a regulação desses aspectos ainda presente. Em primeiro lugar, a entrada já tinha se tornado possível e novos incumbentes passaram a participar do mercado. Em segundo lugar, o controle de preços não era

\footnotetext{
${ }^{1}$ As Linhas Aéreas Especiais são as que ligam os aeroportos centrais das cidades de São Paulo, Rio de Janeiro e Belo Horizonte, além destas até o Aeroporto de Brasília.

${ }^{2}$ Os procedimentos de pedidos de novas freqüências de vôo foram também agilizados, o que conferiu flexibilidade às companhias aéreas no uso dessa variável de competição, apesar das críticas de ter levado a um suposto estado de "excesso de capacidade".
} 
tão estrito. 0 papel da defesa da concorrência no setor de transporte aéreo nacional será discutido na seção 2.2 .

A Terceira Rodada de Liberalização veio remover os controles de preços restantes sobre o setor - leiase, os controles dos reajustes pelo Ministério da Fazenda -, o que aconteceu entre abril e agosto de 2001. A idéia original desta rodada era a de criar uma classe de ligações aéreas chamadas de "liberadas", ao passo que as demais seriam consideradas "controladas" (Portaria DAC $\mathrm{N}^{\circ}$ 672/DGAC, de 16 de abril de 2001), mas, ao final do processo, optou-se for consolidar o regime de liberdade tarifária geral, sem distinção entre ligações em termos de controle, mas apenas de monitoramento (Portaria DAC ${ }^{\circ}$ 1.213/DGAC, de 16 de agosto de 2001).

Paradoxalmente, observou-se que essa rodada final de liberalização da aviação comercial brasileira emergiu em meio a um processo de contestação e forte apelo à re-regulação do setor, onde ganhou força o argumento de que a competição plena não seria tão "saudável" para o mercado. 0 estado financeiro precário das principais legacy carriers brasileiras, com a posterior saída da Transbrasil e Vasp, e a crise da Varig, bem como os supostos problemas de constante instabilidade do setor, alegados pelo regulador, levaram a uma situação transitória, que culminou em 2003, com o novo governo federal, onde, seguindo novas orientações de política setorial, voltou-se a implementar alguns procedimentos de interferência econômica no mercado, objetivando controlar o que foi chamado de "excesso de capacidade" e 0 acirramento da "competição ruinosa" no mercado.

Pelo texto das novas portarias, sobretudo as de n. 243/GC5, de 13 de março de 2003 e n. 731/GC5, de 11 de agosto de 2003, o DAC passa a exercer uma função moderadora, de "adequar a oferta de transporte aéreo, feita pelas empresas aéreas, à evolução da demanda", com a "finalidade de impedir uma competição danosa e irracional, com práticas predatórias de conseqüências indesejáveis sobre todas as empresas". Denominamos este período de "Re-regulação", uma fase onde pedidos de importação de novas aeronaves, novas linhas e mesmo de entrada de novas companhias aéreas, voltaram a exigir estudos de viabilidade econômica prévia, configurando-se uma situação semelhante ao do período regulatório típico; a grande diferença, neste caso, foi que não houve interferência na precificação das companhias aéreas, ou seja, não houve re-regulação tarifária.

A transição por que passa o setor não diz respeito apenas ao fato de que a própria instituição reguladora será substituída, com a constituição da Agência Nacional de Aviação Civil - ANAC, instituída pela Lei n. 11.182, de 27 de setembro de 2005. E também não representa só o fato de que as próprias empresas estão em processo de redefinição, com os debates sobre possíveis incorporações e fusões que datam desde a crise da desvalorização cambial de 1999, e que desaguaram no acordo de compartilhamento entre as duas principais companhias, Varig e TAM (encerrado em abril de 2005), e nas negociações quanto à reestruturação da Varig a partir de então.

Até mais importante do que isso, deve-se enfatizar que o caráter transitório é devido às inúmeras dificuldades e resistências encontradas pelo processo de "flexibilização" até o momento. Isso diz respeito sobretudo ao desconhecimento tanto da sociedade quanto da comunidade do setor, sobre como efetivamente funcionam os mercados desregulamentados de transporte aéreo, e sobre o real significado e impactos de não se ter uma autoridade reguladora atuando ativamente sobre os aspectos econômicos da indústria, deixando os agentes livres para se movimentar e competir.

Por enquanto, dado o estágio atual da aviação, pode-se apenas afirmar que o seu modelo de regulação ainda está sob debates, e que algumas importantes etapas ainda terão que ser percorridas até que se configure um verdadeiro "marco regulatório" do transporte aéreo nacional.

\subsection{Controle de Estruturas e Condutas no Transporte Aéreo Brasileiro}

Uma temática que tem dominado as discussões nessa fase transitória por que passa a Política de Flexibilização, diz respeito à preocupação com o aumento de poder de mercado das empresas incumbentes no ambiente competitivo liberalizado. Dentre os aspectos relevantes destacados pela literatura, encontram-se as causas e conseqüências da maior concentração do setor e a redução da contestabili- 
dade pela existência de barreiras à entrada (TAVARES 1999 e RAGAZZO 2006), ambos com ênfase nos riscos de exercício da dominância na indústria no pós-desregulamentação. Nessa mesma direção tem-se, como ilustração, a iniciativa do DAC de criar o instituto do "monitoramento" de certas ligações aéreas, mesmo após tendo liberalizado totalmente o processo de formação de preços ${ }^{3}$; a idéia de monitorar, nesse caso, está nitidamente ligada ao temor de que um mercado totalmente livre possa acarretar, em última instância, perdas de bem-estar econômico no setor.

Além disso, apesar da clássica crítica ao chamado Paradigma da Estrutura-Conduta-Desempenho, que evoca a relação entre o grau de concentração em um mercado (estrutura) e o poder de oligopólio das empresas (conduta-desempenho), a literatura do transporte aéreo tem sido cada vez mais enfática em apontar que estratégias cooperativas das incumbentes por todo o mundo, têm sido muito utilizadas nessa indústria, sobretudo dentre as companhias aéreas marcadas pela estrutura mais complexa de rede. . . Nitidamente, as evidências da formação de "alianças" e "acordos operacionais" (cf. por ex., PARK 1997), têm se mostrado suficientemente concretas para se inferir que a potencialidade de exercício de poder de mercado na indústria tem crescido substancialmente, pela maior facilidade de coordenação estratégica decorrente daquelas práticas. Por outro lado, a contestabilidade do mercado por parte das companhias aéreas de custo baixo tem crescido substancialmente (BOGUSLASKI et alii, 2004).

Dessa forma, pode-se dizer que o controle dos níveis de concentração e do poder de mercado em setores como o transporte aéreo, tornou-se a principal atribuição das autoridades no novo ambiente competitivo, visando a promoção do bem-estar. O conjunto de mecanismos legais e institucionais voltados a esse objetivo constitui a política antitruste, que objetiva aumentar a eficiência econômica por meio da promoção e estímulo à competição.

A política antitruste é realizada através de instrumentos de intervenção nos quais as autoridades podem atuar, tanto de maneira repressiva quanto preventiva, com relação aos atos considerados lesivos à competição (atos de concentração, como fusões e incorporações, ou práticas de articulação de mercado, como colusão tácita, coordenação de preços e quantidades), sem necessariamente impor condições a todos os participantes do mercado, como nos regimes regulatórios. São dois os seus tipos de processos: o controle da estrutura da indústria, voltado para o controle da formação de poder de mercado; e o controle das condutas, que se preocupa em coibir os abusos do poder de mercado que seja eventualmente detido por uma ou mais firmas da indústria. Esses processos podem envolver duas dimensões: a horizontal, quando as empresas objeto são competidoras em um mercado; e a vertical, que envolve empresas situadas em diferentes níveis da cadeia produtiva.

De acordo com OLIVEIRA (2001), as principais legislações de defesa da concorrência nasceram no final do século XIX nos Estados Unidos e após a Segunda Guerra em vários países europeus. O fenômeno é bem mais recente nos países em desenvolvimento, onde a disseminação de legislações de defesa da concorrência aconteceu de forma mais marcante no final do século XX e início do século XXI. O Brasil enquadra-se neste contexto.

O arcabouço institucional da política antitruste hoje praticada no Brasil foi estabelecido pela Lei de Defesa da Concorrência (Lei n. 8884, de 11 de junho de 1994). Os mecanismos de fomento à competição visam, nos termos da lei, prevenir as chamadas "infrações contra a ordem econômica", pautando-se pelos ditames da livre concorrência e da repressão ao abuso do poder econômico, dentre outros princípios constitucionais.

As instituições governamentais incumbidas da investigação antitruste no Brasil são a Secretaria de Direito Econômico (SDE) e o Conselho Administrativo de Defesa Econômica (CADE), vinculados ao Ministério da Justiça, e a Secretaria de Acompanhamento Econômico (SEAE), no Ministério da Fazenda. Enquanto a SDE tem um papel de acompanhamento e de instauração de processo administrativo para apuração de infrações, o CADE possui caráter judicante, de decisão, julgando os processos instaurados

\footnotetext{
${ }^{3}$ Como visto, por meio da Portaria 1213/DGAC.

${ }^{4}$ As grandes "network airlines" ou "full-service airlines", em comparação com as empresas aéreas de custo baixo, preço baixo, que são em geral, caracterizadas por uma estrutura de rede simplificada, ponto-a-ponto.
} 
por aquela. Já à SEAE cumpre o papel de dar parecer econômico e proceder com investigações, em coordenação com os demais órgãos. Para o futuro, a expectativa é a de que - sendo aprovada a proposta do Projeto de Lei de reforma do Sistema Brasileiro de Defesa da Concorrência (SBDC), ocorra uma reformulação institucional para dinamizar o sistema, de forma que a SDE talvez seja transferida para o CADE, enquanto a SEAE atue nas análises dos mercados sob a incumbência das agências regulatórias (transporte aéreo incluso); outros pontos passíveis de serem reformados são a análise prévia dos atos de concentração pelo $\mathrm{CADE}$, a transformação do mesmo em tribunal, e a redução do número de casos cujo envio para análise do Sistema é mandatório.

Um aspecto relevante da defesa da concorrência em setores regulados, mesmo que parcialmente desregulamentados, diz respeito à superposição de competências entre o órgão regulador, quando este existe, e os organismos antitruste. No caso do transporte aéreo brasileiro, a legislação atribuiu essa função à autoridade reguladora do setor, o Departamento de Aviação Civil (DAC). No entanto, essa função era de pouca importância em função do controle de preços e de entrada que esteve presente na indústria antes da liberalização. Somente com a "flexibilização" da indústria é que emergiu uma maior preocupação com a defesa da concorrência no transporte aéreo, cuja condução coube aos órgãos antitruste.

A execução da política antitruste no transporte aéreo se deu sem conflitos com a autoridade com poder regulador. Sob o ponto de vista legal, há um conflito de competências entre o órgão regulador e os órgãos antitruste. A legislação específica atribui poderes de controle de condutas ao DAC. Na prática, porém, o DAC pouco se utilizou de suas prerrogativas na área antitruste - com poucas exceções, como por exemplo, o episódio da suposta prática de preços predatórios pela Gol, em 2003 -, enquanto os órgãos específicos assumiram o papel principal nos processos ocorridos no período ${ }^{5}$. A criação de uma agência regulatória específica para o setor (ANAC) poderá reavivar a questão da superposição de competências, a exemplo do que ocorre com outros setores regulados no Brasil ${ }^{6}$, apesar da sua lei de criação ter sido clara no que tange à necessidade de harmonização de suas ações com as ações dos órgãos de defesa da concorrência (artigo $6^{\circ}$ da Lei n. 11.182, de 27 de setembro de 2005). A falta de cooperação institucional pode, de acordo com OLIVEIRA (2001), criar custos de transação importantes.

Indubitavelmente, $o$ antitruste, enquanto atuação governamental de maior impacto, tornou-se uma constante na indústria de transporte aéreo, de maneira mais nítida, a partir de 2000. Nessa ocasião, os três órgãos de defesa da concorrência, visando promover uma vigilância constante com relação às movimentações estratégicas das companhias aéreas que se seguiram à desvalorização cambial de 1999, promoveram as seguintes ações no setor:

Como a Tabela 1 deixa claro, o antitruste tem sido um instrumento caracterizador da recente atuação governamental na indústria do transporte aéreo. A mesma Tabela evidencia que a política antitruste cuidou não apenas de processos envolvendo companhias aéreas nacionais, mas também de operações entre companhias internacionais com impacto no mercado doméstico. Como exemplo deste último caso, cite-se a aliança entre duas companhias internacionais que operavam vôos entre a Europa e a América Latina, com o possível objetivo de reforçar a posição destas na competição frente à Varig, empresa nacional que detém participação expressiva nessas ligações e que mantém aliança com outras companhias estrangeiras.

A discussão realizada nesta seção evidencia que é crucial estimular os estudos relativos à política antitruste e suas aplicações no transporte aéreo, objeto do presente trabalho. A próxima seção visa dar uma contribuição no sentido de aplicar uma modelagem da Organização Industrial para uma investiga-

\footnotetext{
${ }^{5}$ Conforme chegou a conclusão o Parecer SEAE n. 008 /COGDC-DF/SEAE/MF: “O DAC é um admirável órgão técnico. Os nossos índices de acidente aeronáutico estão dentre os mais baixos do mundo, graças à eficiente fiscalização do DAC. Mas, jamais efetuou a análise de atos de concentração no setor aéreo, no âmbito da Lei ${ }^{\circ} 8.884 / 94$. Posição compreensível, pois nunca foi legalmente competente para tanto" (SEA, 2001).

${ }^{6} \mathrm{~A}$ respeito das configurações institucionais possíveis na divisão de trabalho entre as autoridades de defesa da concorrência e de regulação, veja-se OLIVEIRA (2001).
} 
Tabela 1 - Principais Investigações Antitruste Efetuadas no Transporte Aéreo

\begin{tabular}{|c|c|c|c|}
\hline Data do processo & Tipo de processo & Objeto & Companhias \\
\hline Março de 2000 & Conduta & $\begin{array}{l}\text { Aumento "coordenado e uni- } \\
\text { forme" de preços, na Ponte Aérea } \\
\text { RJ - SP, após reunião entre repre- } \\
\text { sentantes das empresas. Julgado } \\
\text { pelo CADE em Setembro de } 2004 \text {. }\end{array}$ & $\begin{array}{l}\text { Varig, TAM, Vasp e } \\
\text { Transbrasil }\end{array}$ \\
\hline Março de 2000 & Conduta & $\begin{array}{l}\text { Redução “coordenada e uniforme" } \\
\text { da comissão das agências de via- } \\
\text { gem. }\end{array}$ & $\begin{array}{l}\text { Varig, TAM, Vasp e } \\
\text { Transbrasil }\end{array}$ \\
\hline Abril de 2000 & Conduta & $\begin{array}{l}\text { "Desequilíbrio na competição do } \\
\text { setor" alegada pela TAM devido à } \\
\text { inadimplência da Vasp. }\end{array}$ & Vasp e demais \\
\hline Maio de 2000 & Estrutura e Conduta & $\begin{array}{l}\text { Acordo operacional, seguido da re- } \\
\text { dução de oferta de assentos e au- } \\
\text { mento de preços. }\end{array}$ & TAM e Transbrasil \\
\hline Maio de 2000 & Estrutura e Conduta & $\begin{array}{l}\text { Venda de aeronaves e transferên- } \\
\text { cia de linhas. }\end{array}$ & Varig e Vasp \\
\hline Julho de 2000 & Estrutura & $\begin{array}{l}\text { Assinatura de Carta de Intenções } \\
\text { para a constituição da Plata, em- } \\
\text { presa de comercialização eletrô- } \\
\text { nica de passagens aéreas e outros } \\
\text { serviços relacionados a turismo. }\end{array}$ & Varig e TAM \\
\hline Fevereiro de 2001 & Estrutura e Conduta & $\begin{array}{l}\text { Denúncias de restrições à entrada: } \\
\text { combinação de descontos no mês } \\
\text { em que a Gol iniciou as operações; } \\
\text { e lobby do Sindicato das Empresas } \\
\text { Aeroviárias sobre o DAC para impe- } \\
\text { dir aceitação de novas empresas. }\end{array}$ & Varig e TAM \\
\hline Maio de 2001 & Estrutura & $\begin{array}{l}\text { Aliança entre companhias interna- } \\
\text { cionais em rotas entre Europa e } \\
\text { América do Sul. }\end{array}$ & $\begin{array}{l}\text { British Airways e } \\
\text { Iberia }\end{array}$ \\
\hline Fevereiro de 2003 & Estrutura & $\begin{array}{l}\text { Assinatura de Protocolo de En- } \\
\text { tendimentos entre as duas mai- } \\
\text { ores companhias para sua fusão } \\
\text { gerando significativo aumento da } \\
\text { concentração de mercado, seguido } \\
\text { de assinatura de Acordo de Preser- } \\
\text { vação de Reversibilidade da Ope- } \\
\text { ração (APRO), o primeiro da histó- } \\
\text { ria do SBDC. A fase inicial envol- } \\
\text { veu um acordo de "code share”. A } \\
\text { partir de recomendação da SEAE, } \\
\text { o CADE aprovou, em fevereiro de } \\
2005 \text {, o fim desse compartilha- } \\
\text { mento. }\end{array}$ & Varig e TAM \\
\hline
\end{tabular}


ção antitruste no setor. Será abordada, para esses fins, a alegação de colusão pelas empresas aéreas, na Ponte Aérea Rio de Janeiro - São Paulo (primeira linha da Tabela 1).

\section{MODELAGEM DA CONDUTA E INVESTIGAÇÃO DE COMPORTAMENTO COLUSIVO}

\subsection{Descrição da Conduta sob Análise}

A conduta sob análise é a que foi objeto do processo administrativo instaurado em 27 de março de 2000, com base na instrução de Averiguação Preliminar realizada pela SDE, decorrente da representação formulada pela SEAE; um parecer da SEAE foi emitido em setembro de $2001,{ }^{7}$ e o caso foi julgado no CADE em setembro de 2004; as companhias foram condenadas "com aplicação de multa de um por cento pertinente ao valor do faturamento bruto obtido sobre o Mercado Relevante definido como o da Ponte Aérea entre os aeroportos Santos Dumont (Rio de Janeiro) e Congonhas (São Paulo) referente ao exercício de 1999 (ano da infração), nos termos do art. 23, I c/c art. 27 e seus incisos da Lei n. ${ }^{\circ}$ 8.884/94 e art. 11 da Lei $n .^{\circ}$ 9.021/95" (SCALLOPE e FARINA, 2004).

A Tabela 2 apresenta a seqüência de acontecimentos pertinentes ao caso.

Tabela 2 - Fatos sob Investigação

\begin{tabular}{l|l}
\hline Data & Evento \\
\hline $8 / 3 / 99$ & $\begin{array}{l}\text { Reunião entre representantes das quatro companhias aéreas em hotel } \\
\text { Sofitel, em São Paulo - SP, amplamente noticiada pela imprensa, mas } \\
\text { cujo assunto principal não foi revelado ((FARINA, 2004)) menciona que, } \\
\text { segundo a imprensa, a reunião visava discutir “a criação da Agência Na- } \\
\text { cional da Aviação Civil, a crise no setor e eventual cooperação na área } \\
\text { operacional"). }\end{array}$ \\
\hline $8 / 9 / 99$ & $\begin{array}{l}\text { Houve aumento de preços das quatro companhias aéreas em percentual } \\
\text { uniforme de dez por cento. Segundo a SEAE, o tempo decorrido entre o } \\
\text { registro no sistema ATPCO do aumento pela Varig e inserção de uma nota } \\
\text { pela TAM anunciando seu aumento foi de cerca de cinquenta minutos. }\end{array}$ \\
\hline
\end{tabular}

A seqüência cronológica dos fatos, apresentada na Tabela 2, sugere que a reunião entre os representantes das quatro companhias aéreas que operam a ligação conhecida como "Ponte Aérea Rio-São Paulo"9 pode estar relacionada ao aumento de preços em percentual uniforme de $10 \%$, ocorrido seis dias

\footnotetext{
${ }^{7}$ Este parecer recomendava a punição da conduta ocorrida em agosto de 1999, “com fulcro no Art. 20, inciso I cc. Art. 21 inciso I da Lei no 8.884/94, uma vez a mesma apresentou efeitos anticompetitivos sem justificativas aceitáveis do ponto de vista da teoria econômica", a proibição de utilização da ferramenta de First Ticket Date do Sistema de tarifas da Airline Tariff Publishing Company, ATPCO, por parte das companhias aéreas nacionais de aviação civil, e a abertura de Processo Administrativo contra a própria ATPCO.

${ }^{8}$ Ao todo, foram três votos pela condenação (PRADO, 2004, SCALLOPE, 2004, PFEIFFER, 2004), contra dois votos pedindo o arquivamento do processo (ANDRADE, 2004, FARINA, 2004). Houve também um debate acerca de qual multa seria apropriada para o caso; há que se enfatizar que também a tomada de decisão quanto à multa adequada para os casos considerados nocivos, deve ser baseada em modelagem estrutural, dado que uma sinalização errônea por parte das instituições pode representar um incentivo para o recrudescimento das práticas anti-concorrenciais.

${ }^{9}$ Esta ligação conecta o aeroporto Santos Dumont, no Rio de Janeiro e o aeroporto de Congonhas, em São Paulo. Ambos são aeroportos localizados em zonas centrais e sua operação é restrita a vôos domésticos. Esta ligação tem características diferentes da ligação entre os aeroportos do Galeão e de Cumbica nas mesmas cidades, que estão localizados a maior distância das concentrações urbanas principais e se caracterizam por receberem a maior parte das ligações internacionais que têm o Brasil como origem ou destino. Apesar do predomínio das ligações internacionais, estes dois últimos também recebem um volume
} 
depois. As quatro empresas detinham na época a totalidade da oferta de assentos em vôos regulares na Ponte Aérea Rio-São Paulo. A Gol Linhas Aéreas Inteligentes somente iniciou operações no mercado em 2002, tendo primeiro entrado no par-de-aeroportos Congonhas - Galeão (janeiro de 2001).

O Processo Administrativo aberto pela Secretaria de Direito Econômico foi fundamentado na suspeita de "elevação concertada de preços" (do tipo paralelismo plus ${ }^{10}$ ). De acordo com o parecer da SEAE, avaliando-se todas as possibilidades "(...) restou apenas a conclusão de que a única explicação para a uniformidade e simultaneidade dos reajustes é a realização de comunicação prévia e expressa entre as empresas." - Secretaria de Acompanhamento Econômico (2001). A SEAE sugeriu ainda que a comunicação de preços contou com um elemento adicional, o sistema $\mathrm{ATPCO}^{11}$, que facilitaria o intercâmbio de informações entre as companhias aéreas. Esse intercâmbio, não restrito à tarifa praticada, pode ter servido como veículo de uma colusão tácita entre as companhias aéreas, mesmo que estas não tenham engajado em comunicação direta.

Para se entender a importância do sistema ATPCO no processo antitruste, vale a pena analisar os modernos sistemas de publicação de informações na indústria de transporte aéreo. De acordo com SHAW (1999), o método de disseminação de preços nessa indústria evoluiu recentemente de um manual de tarifas impresso, com contatos telefônicos para realização de reservas, para o desenvolvimento de sistemas de distribuição global. Esses sistemas, desenvolvidos a partir da década de setenta nos Estados Unidos, propiciam o acesso instantâneo a bases de dados de preços atualizadas várias vezes ao dia quando necessário. O advento desses sistemas fez com que a estrutura de tarifas, mais complexa, gerasse uma instabilidade dos preços médios (yields) em épocas de competição acirrada.

Os sistemas desse tipo têm a grande vantagem de permitirem a redução de custos de transação na indústria. Entretanto, o seu aparecimento gerou preocupações de natureza regulatória, inicialmente nos Estados Unidos e posteriormente na Europa. São duas as preocupações principais. Primeiramente, o controle de um sistema desse tipo por uma companhia aérea a coloca em posição de criar restrições verticais anti-competitivas (LEVINE, 1987).

Em segundo lugar, a publicação instantânea de mensagens junto com os preços permitiria o tráfego de informação entre os incumbentes da indústria, e a possível combinação tácita de preços. Essas informações podem não ser postadas de forma explícita, mas sim de forma a sugerir alguma ação coordenada. Por exemplo, as companhias podiam publicar o prazo de validade de uma determinada tarifa, com a data de sua entrada em vigor e a sua expiração. Como não há obrigação de que a tarifa efetivamente entre em vigor na data marcada, a publicação de tarifas para vigência futura pode ser parte de um processo iterativo em que os incumbentes decidem a sua estrutura de tarifas como se estivessem envolvidos em uma negociação de combinação de preços. É sobre este segundo elemento que se concentra a reprovação da SEAE na conduta sob análise, sendo que este aspecto foi condenado em jurisdições de países desenvolvidos e gerou acordos de cessação de prática, também propostos pela SEAE.

Um processo de liderança de preços pode, assim, emergir da interação estratégica entre as firmas da indústria. No presente caso, a firma líder poderia ser a Varig, por conta de seu elevado market share no mercado, sendo seguida pelas demais firmas através de um acordo tácito, não explícito, entre estas. Por isto, conforme FORGIONI (1998), nas legislações antitruste norte-americana e européia o ilícito de conduta na liderança de preços ocorre quando há acordo, concertação ou combinação entre as partes. Na prática, a comprovação do conluio é deduzida das circunstâncias do caso. FARINA (2004) sugere que haveria alternância entre no posto de líder entre a Varig e a TAM, uma situação que, em princípio é pouco provável, em se considerando que a ascensão da TAM como companhia aérea com

importante de ligações domésticas; mas nos dois aeroportos centrais não se operam rotas internacionais importantes. Há ligações entre o aeroporto central de uma cidade e o internacional da outra e vice-versa; vide mais detalhes em 3.2.

${ }^{10}$ Onde o plus é referente à reunião prévia entre os dirigentes das companhias aéreas.

${ }^{11}$ Airline Tariff Publishing Company, o líder mundial em coleta e distribuição de dados de preços da indústria de transporte aéreo. 
alta participação de mercado nesta ligação era muito recente e ainda não estava consolidada no período sob análise (1999) ${ }^{12}$.

Considerado em si mesmo, o fato de se comprovar que uma reunião entre os empresários levou a práticas coordenadas de mercado (colusão), já constitui conduta que caracteriza infração à ordem econômica, por aplicação direta dos incisos I e II do artigo 21 da Lei 8.884/94. A dificuldade desta iniciativa está relacionada à comprovação de que realmente houve combinação, o que pode ser sanado por simples presunção, dado que houve o encontro. Nos Estados Unidos, por exemplo, os empresários de um setor são proibidos de se reunir ou até mesmo de trocar correspondências ou telefonemas. Por exemplo, o ex-presidente da American Airlines, Robert Crandall, já foi processado pelo governo norte-americano por uma famosa conversa por telefone entre ele e Howard Putnam, da Braniff, sobre combinação de preços (WHITE, 1999).

PHLIPS (1987), introduz um importante aspecto a essa questão, ao questionar uma série de proposições tradicionais acerca do que se considera a competição normal em um mercado. Duas delas dizem respeito à prática concertada de preços: "A competição normal implica que a cada firma é livre para estabelecer, de forma independente, seus preços" (Proposição 1) e "Ela não é compatível com movimentações simultâneas de preço" (Proposição 2). Como resultado, coloca o autor, o pensamento antitruste tradicional consideraria que movimentações paralelas e concertadas de preços em mercados oligopolísticos comprovariam a existência inequívoca de colusão. Esta parece ser a visão da SEAE ao buscar aplicar a Lei 8.884/94, como descrito em seu Parecer (Secretaria de Acompanhamento Econômico, 2001).

Entretanto, continua o autor, essa forma de pensar os mercados oligopolísticos falha em reconhecer o seu caráter inerente de interdependência estratégica entre as firmas, um conceito de comportamento corporativo já incorporado à Organização Industrial (cf. MAS-COLELL et alii 1995). Esta definição está presente na consideração do que seja um equilíbrio não-cooperativo (ou Equilíbrio de Nash) em um mercado com poucas firmas, isto é, a situação de mercado onde as firmas perseguem seus objetivos, considerando o que as concorrentes fazem, mas sem uma racionalidade de grupo (cooperação). 0 padrão de equilíbrio não-cooperativo deve, assim, ser o objetivo perseguido pelas autoridades antitrustes em um mercado, do ponto de vista econômico.

Uma conclusão é diretamente derivável do conceito de equilíbrio não-cooperativo: se uma firma resolve aumentar seus preços, como no caso sob estudo, segue-se que o simples fato das demais também se movimentarem não é incompatível com o equilíbrio não-cooperativo, como também não é incompatível com um a situação de conluio. Assim, tem-se que a movimentação simultânea, por si só, não fornece base suficiente de distinção entre competição e colusão, e, portanto, não pode servir de fundamento para uma análise antitruste, no que tange os parâmetros da teoria econômica. Sob o ponto de vista jurídico, pode até representar infração à lei, mas não caracteriza um comportamento efetivamente colusivo, dado que o próprio conceito de competição não pode ser também dissociado do conceito de interdependência entre firmas.

O mesmo autor (PHLIPS, 1987) promove uma reformulação das proposições tradicionais expostas, adequando-as ao conceito de interdependência estratégica: " $\mathrm{Em}$ um equilíbrio não-cooperativo, cada firma é livre para estabelecer seus preços, mas não é do interesse de nenhuma fazê-lo de forma independente" (Proposição 1*) e "O equilíbrio não-cooperativo é compatível com movimentações simultâneas" (Proposição 2*). Assim, chega-se ao resultado de que uma ação concertada de preços não se trata necessariamente de uma evidência de prática de cartel.

Note-se, portanto, que há aspectos jurídicos envolvidos no julgamento da conduta em análise que fogem ao escopo deste trabalho. Não se busca, portanto, investigar nem a possível ligação entre a reunião de empresários com o subseqüente aumento de preços, e nem as características de simultaneidade

\footnotetext{
${ }^{12}$ De fato, uma consulta aos dados utilizados nesta pesquisa (vide detalhes na Seção 4) mostra que o market share da Tam somente se tornou maior do que o da Vasp e da Transbrasil a partir de maio de 1999, quanto o acordo code-share entre as mesmas foi rompido. Assim, torna-se tarefa árdua qualificar como "líder" uma companhia que três meses antes estava em último lugar na participação de mercado nesta rota caracterizada por ser um triopólio.
} 
de movimentação como indicativa de colusão. Ao contrário, buscar-se-á, por meio da definição do mercado relevante, considerado na próxima seção, promover uma modelagem do que seria um afastamento do equilíbrio não-cooperativo, independentemente desses fatos apurados (sub-seção 3.3).

O exercício realizado nas próximas seções busca, portanto, definir padrões de movimentação de preços, ou melhor, referências possíveis, para as estratégias das empresas: referencial de equilíbrio nãocooperativo versus referencial de cooperação ou de colusão. Tais referências podem ser comparadas diretamente com a conduta observada em agosto de 1999 e permitirão inferências sobre se houve ou não comportamento colusivo sob o prisma econômico, sem, no entanto, entrar no mérito das prescrições legais pertinentes. Esta abordagem apresenta a vantagem de não necessitar que se comprove qualquer forma de combinação prévia e não depender de critérios qualitativos como os de "paralelismo de conduta". ${ }^{13}$

\subsection{Mercado Relevante: A Ligação Congonhas-Santos Dumont}

A delimitação do mercado relevante é etapa fundamental de toda investigação antitruste. Em uma definição bastante usual, que foi apresentada nas Diretrizes para a Análise de Fusões Horizontais da Federal Trade Commission norte-americana, o mercado relevante é definido com "um produto ou grupo de produtos e uma área geográfica na qual ele é produzido ou vendido, tal que uma hipotética empresa maximizadora de lucros, não sujeita a regulação de preços que seja o único produtor ou vendedor, presente ou futuro, daqueles produtos naquela área, poderia provavelmente impor pelo menos um pequeno mas significativo $e$ não transitório aumento no preço, supondo que as condições de venda de outros produtos se mantêm constantes. Um mercado relevante é um grupo de produtos e uma área geográfica que não excedam o necessário para satisfazer tal teste". ${ }^{14}$

Na sua dimensão de produtos, a análise trata do transporte regular de passageiros na Ponte Aérea Rio de Janeiro - São Paulo; trata-se, indubitavelmente, da ligação mais importante do transporte aéreo brasileiro, por sua densidade de tráfego e sua representatividade - viagens tipicamente por motivos de negócios, ligação de dois relevantes centros industriais do País e presença de todas as maiores companhias aéreas nacionais.

Assim, a definição de "mercado relevante", ressalta que nesse tipo de análise, o conceito de mercado é compreendido de forma que se possa analisar "os efeitos, para o consumidor de determinado produto ou serviço, de alguma conduta empresarial ou concentração" (TAVARES, 1999). A hipótese básica assumida por este trabalho é que a ligação Congonhas - Santos Dumont é um mercado suficientemente estratégico, para as empresas aéreas brasileiras adotarem ações específicas a ele.

Pode-se defender o argumento do enfoque nessa ligação, colocando que, em geral, as companhias aéreas divulgam campanhas publicitárias e anúncios de promoções em separado para este mercado, e, até recentemente, as decisões de reajustes das tarifas das outras ligações do País eram feitas de forma descasada com as decisões relativas a essa ligação. Até mesmo as autoridades aeronáuticas possuíam no passado, mecanismos especiais de regulação para a rota, como a exceção para as empresas nacionais do antigo pool da Ponte Aérea de operar na ligação, o que a diferenciava das demais Linhas Aéreas Especiais, caracterizadas pela operação de regionais.

Outro argumento importante diz respeito à magnitude de tráfego e lucros da ligação, quando comparadas com o resto do transporte aéreo nacional. Por exemplo, no biênio 1997-98, os lucros neste mercado representaram um terço dos lucros em todo o transporte regular doméstico das empresas nacionais. Além disso, as receitas na ligação somaram mais do que as receitas nas demais Linhas Aéreas Especiais, que poderiam ser consideradas linhas correlatas em um "mercado relevante".

Pode-se, portanto, defender a premissa de que a ligação isoladamente, pode ser tratada como "mercado relevante", como, aliás, seguem a Secretaria de Acompanhamento Econômico (2001) e FARINA

\footnotetext{
${ }^{13}$ Secretaria de Acompanhamento Econômico (2001).

${ }^{14}$ Tradução de MELLO (2002).
} 
(2004). Entretanto, deve-se enfatizar de que não há como defender que não haja interações entre a ligação Congonhas-Santos Dumont e as demais ligações (pares de aeroportos) entre as cidades do Rio de Janeiro e São Paulo. De fato, isso pode ser ilustrado pela entrada da Gol no Aeroporto do Galeão, em 2001, quando esta passou a operar a ligação Galeão-Congonhas. Este evento teve, certamente, efeitos importantes com relação à Ponte Aérea, e foi, de certa forma a causadora da "guerra de preços" observada nos meses seguintes naquele mercado.

Como será visto na seção 3.4, o presente trabalho buscou efetivamente controlar os efeitos competitivos entre pares de aeroportos na rota Rio de Janeiro - São Paulo. Infelizmente, aperfeiçoamentos como a hipótese de contato multimercado entre esta rota e outras rotas do transporte aéreo nacional, ficam para futuras extensões. Isso coloca este estudo dentre a grande maioria das pesquisas na literatura, que trata exogenamente o contato multimercado, sendo a modelagem em EVANS e KESSIDES (1994) uma importante exceção. Maiores detalhes sobre o conceito de "mercado relevante" e seus problemas, vide SALGADO (1997), WERDEN (2000), dentre outros.

Uma outra definição importante diz respeito ao período a ser considerado no estudo. Essa escolha é crucial tendo em vista a definição dos eventos deslocadores da conduta competitiva, que serão controlados por meio de variáveis dummy, na modelagem da seção 3.4. Para a presente investigação antitruste, o período sob investigação foi de 1997 a 2001. Nele, estão englobados os seguintes eventos (chamados, daqui em diante, de "eventos relevantes"):

1. Medidas de desregulamentação de 1997-98 (Segunda Rodada de Liberalização), onde foi estimulada a competição via preços (ampliação das bandas tarifárias) e foi incrementada a contestabilidade aos mercados nas Linhas Aéreas Especiais; neste período ocorreu o incêndio no aeroporto Santos Dumont e o fim do pool da Ponte Aérea;

2. Mudança de regime cambial e desvalorização da moeda, em janeiro de 1999 (representou um choque relevante nos custos das companhias aéreas e em suas expectativas de lucratividade futura); considerou-se que esse período engloba até o final daquele ano, quando a taxa de câmbio começou a recuar, valorizando-se gradativamente;

3. Período alegado como de "coordenação de preços" e colusão: a partir de agosto de 1999. Em tese, pelo menos a Varig e a TAM mantiveram os mesmos preços até o reajuste de junho de 2000. Entretanto, na prática, como tanto Vasp quanto Transbrasil reduziram seus preços no início de 2000 , optou-se aqui por considerar o período "mais representativo" deste evento como sendo de agosto a dezembro de 1999. Isso permite que se minimize os efeitos que outros eventos pudessem exercer sob a conduta desse período, e que se façam inferências mais cristalinas sobre a existência ou não de colusão;

4. Período posterior ao reajuste de preços autorizado em agosto de 2000; também envolve parte do período do acordo de code-share TAM-Transbrasil;

5. Período dos descontos ("guerra de preços") concedidos logo após a entrada da Gol na ligação Galeão-Congonhas; nesta ocasião (entre fevereiro e maio de 2001), as companhias aéreas ofereceram tarifas especiais, seja de fora-do-pico, seja de fins-de-semana ou mesmo irrestritos, típicos de uma conduta reativa à entrante; houve também a fracassada tentativa de "re-entrada" da Transbrasil. Entretanto, houve a pressão de custos ocasionada pela desvalorização cambial daquele ano, com conseqüente aumento dos preços de insumos.

Ressalta-se que os eventos relevantes, acima listados, foram potenciais deslocadores da conduta competitiva das companhias aéreas na ligação sob estudo. Espera-se, ex-ante, que o evento 1 levasse a um estado mais competitivo no mercado, enquanto 3 e 4 acarretassem situações que, em princípio, seriam menos competitivas; já o efeito do evento 2 na conduta, e mesmo o do evento 5 (que envolve 
também um período de desvalorização cambial), é uma questão empírica. ${ }^{15}$ A análise da subseção 3.3 e, sobretudo, a seção 4, cuidará de fazer uma investigação ex-post - isto é, com base nas estimações dos modelos - destas correlações esperadas ou alegadas.

\subsection{Arcabouço da Modelagem da Conduta Competitiva na Ligação}

A modelagem aqui adotada para investigação da alegação de abuso de poder de mercado por parte das companhias aéreas, foi baseada na chamada Nova Organização Industrial Empírica (NOIE). BRESNAHAN (1989), promove uma clássica descrição dessa abordagem, sintetizando-a por meio de dois elementos básicos:

i. Nela, tanto o comportamento da firma quanto da indústria, com relação às variáveis estratégicas preço e quantidade, são definidos e representados por parâmetros desconhecidos a serem estimados; desta forma, o manejo econométrico das equações comportamentais básicas de mercado permite a direta identificação do que é chamado de "parâmetro de conduta";

ii. Por decorrência, e utilizando-se das estimações da conduta, o-se das estimardenaitir|ao ra de se uma base de dadosas inferências sobre poder de mercado tornam-se factíveis quantitativamente, e na forma de simples testes de hipóteses. Assim, tem-se uma abordagem com elevada demanda por dados estatísticos, mas que viabiliza a comparação de hipóteses distintas como, por exemplo, a da concorrência perfeita (ausência de interação estratégica) e da maximização conjunta de lucros (coordenação ou colusão), bem como hipóteses intermediárias, típicas de modelos oligopolísticos.

Buscou-se, assim, desenvolver um modelo de equações simultâneas, representativo da competição na ligação Congonhas - Santos Dumont, e baseado nesta corrente da Organização Industrial.

\subsubsection{Demanda}

No que diz respeito à demanda, a hipótese básica adotada neste trabalho é a de produto heterogêneo entre as firmas. Desta forma, tem-se que o serviço de transporte aéreo regular fornecido por cada uma das operadoras da Ponte Aérea, é percebido como diferenciado pelos consumidores. Esta hipótese enseja maior discussão, dado que tanto a SEAE (SEA, 2001), quanto à maioria dos conselheiros do CADE (FARINA, 2004, PFEIFFER, 2004, SCALLOPE, 2004, ANDRADE, 2004), optaram explicitamente por seguir na direção contrária, ou seja, assumem que o produto é homogêneo nesta ligação.

Indubitavelmente, tem-se que, dependendo das potencialidades do mercado de transporte aéreo sob análise, e do quão elevado espera-se que seja o grau de substitutibilidade entre as ofertantes, pode vir a ser razoável assumir a homogeneidade do produto. Um exemplo importante em literatura encontra-se em BRANDER e ZHANG (1990), em um estudo sobre a competição entre American Airlines e United Airlines em um conjunto de rotas da aviação comercial norte-americana. De fato, os autores utilizam-se da própria seleção das rotas em sua amostra - isto é, apenas aquelas caracterizadas como efetivo "duopólio" dessas companhias aéreas - como forma de tornar mais realista essa proposta de representação do produto.

O procedimento acima ilustrado não é imune a críticas e, além disso, está visivelmente em discordância com a recente literatura acerca dos padrões concorrenciais do transporte aéreo. A partir de LEVINE (1987), mas, sobretudo com os trabalhos de BORENSTEIN (1989) e BERRY (1990), passou-se a entender a competição no setor como sendo a rivalidade entre firmas que são distintas entre si, que possuem atributos diversos que são efetivamente percebidos pelo consumidor. Estes atributos distintos adviriam de:

\footnotetext{
${ }^{15}$ Não é óbvia a relação entre um choque em custos e o sentido da variação na conduta competitiva. Este debate também existe pelo lado do efeito de deslocamentos de demanda (GREEN e PORTER, 1984, ROTEMBERG e SALONER, 1986).
} 
1. Vantagens competitivas ao nível da rota, como, por exemplo, diferentes escalas de operação, com diferentes números de freqüências diárias de vôo, o que gera assimetrias com relação às distâncias entre horário de vôo ofertado e horário desejado de partida (chamado de "schedule delay"); diferentes posicionamentos de oferta nos horários de pico, com diferentes apelos aos passageiros com viagens por motivos de negócios; diferentes padrões de serviços de atendimento ao consumidor, presença de frills antes e durante o embarque, tipo de aeronave, etc; e

2. Vantagens competitivas ao nível do aeroporto e da cidade, por exemplo, tamanhos diferentes de rede doméstica e internacional; participação em alianças globais de companhias aéreas; número de cidades atendidas; níveis de propaganda; características do programa de milhagem; restrições verticais com relação aos agentes de viagem, etc. É nesta linha de investigação que surgiu uma geração de artigos em transporte aéreo, como BORENSTEIN (1991), EVANS e KESSIDES (1993), BERRY et alii (2006), BERECHMAN e SHY (1996), SALVANES et alii (2003), RICHARD (2003) dentre outros.

Ademais, tem-se que, com o advento das "companhias aéreas de custo baixo, preço baixo", e sua penetração cada vez maior nos mercados aéreos em todo o mundo, a tendência da literatura tem sido a de considerar este setor como típico de produto diferenciado, dada a nítida distinção entre os padrões de serviço e a forma de atuação das novas entrantes e as incumbentes, companhias aéreas baseadas em redes. Exemplos desse tipo de análise, onde se assume o produto diferenciado entre as chamadas "network carriers" e as "low cost carriers" são WINDLE e DRESNER (1999), BOGUSLASKI et alii (2004), OLIVEIRA e HUSE (2004) e OLIVEIRA (2006). Também conferir TRETHEWAY (2004).

No caso do mercado em tela, a Ponte Aérea Rio de Janeiro - São Paulo, tem-se que a ligação sempre esteve muito associada à imagem do período de operação em pool das empresas, situação que permaneceu por quarenta anos no mercado (até julho de 1998). Observava-se nitidamente que, sob condições de operações estritamente conjuntas, que incluíam desde vendas e check-in comuns, até vôos compartilhados e endosso total dos bilhetes aéreos, não havia incentivos e nem mecanismos que viabilizassem uma efetiva diferenciação entre as operadoras. Não se pode esquecer, entretanto, que, dentro do período amostral aqui considerado, aborda-se uma fase de coexistência entre o pool e as recém-entradas companhias regionais (TAM e Rio-Sul), e, já nesse caso, era cristalina a diferenciação de produto no sentido de Borenstein-Berry; desta forma, o serviço oferecido pelo pool era claramente percebido como diferenciado do serviço oferecido pelas regionais - vôos mais freqüentes, maior número de balcões de check-in e com menor tempo de espera, maior flexibilidade no uso do bilhete, etc).

Com a Segunda Rodada de Desregulamentação, no final de 1997 e início de 1998, e conseqüente aumento da contestabilidade no mercado - sobretudo com a flexibilização da entrada nas chamadas Linhas Aéreas Especiais -, observou-se a materialização de alguns fenômenos de relevância que contribuíram com o reforço dos aspectos de diferenciação de produtos na ligação:

- Fim do pool da Ponte Aérea (1998) e conseqüente individualização do atendimento e serviço ao passageiro em geral; cada companhia aérea passou, desde então, a buscar formas próprias de abordagem do consumidor;

- Introdução de programas de milhagem, o que tornou mais relevante a competição visando a diferenciação em termos de tamanho da rede doméstica e internacional conectada aos aeroportos do Rio de Janeiro e São Paulo; por exemplo, a entrada da Varig na Star Alliance, em 1997, proporcionou um atributo distintivo na busca da fidelização do passageiro freqüente, dado que uma aliança deste porte geralmente incrementa as possibilidades de conexão internacional dos passageiros, bem como torna mais atrativo o seu programa de milhagem frente à concorrência ao nível da rota; esse é um fator de destaque na Ponte Aérea, onde o passageiro típico é um viajante freqüente. Além disso, há que se enfatizar que os programas de milhagem apresentavam diferentes estruturas de premiação (cálculo por meio de milhas, na Varig, e por meio de trechos, 
na TAM), bem como que algumas operadoras não possuíam programas dessa natureza (Vasp e Transbrasil);

- "Corrida" por freqüências a partir 1998; isso deixou clara a existência de graus diferenciados de posicionamento das freqüências ao longo de um dia de operação, bem como nos horários de pico e aos finais de semana. Por exemplo, OLIVEIRA (2005) reporta que, em 1999, enquanto o tempo médio entre dois vôos da Varig era de quarenta e cinco minutos, a Vasp possuía um tempo médio de mais de uma hora e meia; isso representava um atributo fundamental aos olhos do passageiro mais sensível ao horário;

- Coexistência de diferentes tipos de aeronaves. A TAM proporcionou dois exemplos indicativos de diferenciação de produto por conta da aeronave operada: em primeiro lugar, quando utilizava o Fokker 100, equipamento com baixo nível de reputação junto ao público da Ponte Aérea; posteriormente, em 1999, quando introduziu os Airbus A319, configurado com classe econômica e também executiva, além de monitores de vídeo individual em todas as poltronas, o que visivelmente proporcionou um serviço de bordo diferenciado das demais competidoras;

- Dificuldades financeiras da Vasp e Transbrasil. Isso gerava incentivos para que essas companhias adotassem estratégias agressivas de geração de caixa (com descontos mais altos, sobretudo no caso da Vasp, ${ }^{16}$ ) ou de necessidade de operação conjunta (o que gerava problemas constantes de identidade da marca, no caso da Transbrasil); em ambos os casos, abriu-se espaço para a operação em um nicho menor de mercado, distinto do mainstream, servido por varig e TAM, e que visava o consumidor com maior sensibilidade a preços - vide o resultado da pesquisa junto aos passageiros da ligação, feita por OLIVEIRA (2005).

Uma segunda hipótese com relação à demanda diz respeito à estrutura da substitutibilidade entre os bens, problema típico de modelagem de demanda com produto heterogêneo. Como simplificação analítica, adotar-se-á a hipótese do "oponente médio", desenvolvida por SLADE (1986). Nela, modelase a competição como se fosse em forma de duopólio - a firma em consideração versus uma média poderada das demais -, de forma que a matriz de elasticidades-preço cruzadas é reduzida para facilitar o tratamento econométrico do modelo. ${ }^{17}$ A função demanda de cada firma é definida, portanto, como sendo:

$$
q_{i}=q\left(p_{i}, p_{i}^{-}, \Gamma, \beta\right)=\beta_{0}+\beta_{1} p_{i}+\beta_{2} p_{i}^{-}+\phi(\Gamma)
$$

Onde $q_{i}$ é a quantidade demandada da firma $i, p_{i}$ e $p_{i}^{-}$são, respectivamente, o próprio preço e o preço do oponente médio, $\Gamma$ é um vetor de deslocadores exógenos de demanda, e $\beta$ é um vetor de parâmetros.

O arcabouço de demanda em (1) impõe, sem dúvida, estrutura mais inflexível sobre os parâmetros estruturais das firmas no mercado, sobretudo nos padrões de substituição entre elas. Neste ponto ele está em desvantagem em relação aos recentes avanços da literatura de organização industrial empírica, que enfatizam a flexibilidade proporcionada pelas formas funcionais, por exemplo, os modelos de demanda com orçamentação em múltiplos estágios (HAUSMAN et alii, 1994), os de escolha discreta com coeficientes aleatórios (BERRY et alii, 1995), e os modelos de métrica de distância (Pinkse et alii, 2002). Para um aperfeiçoamento neste sentido, vide OLIVEIRA (2005), que utiliza orçamentação em dois estágios com aplicação à Ponte Aérea.

\footnotetext{
${ }^{16} \mathrm{Na}$ verdade, a Vasp posicionava-se como uma companhia low fare, sem ser low cost. Essa estratégia foi em muito prejudicada com a entrada da Gol, em 2001, no mercado brasileiro, e em 2002, na Ponte Aérea.

${ }^{17} \mathrm{~A}$ ponderação, no que diz respeito à construção das caraterísticas do oponente médio, em geral, deve ser feita de forma a dar mais importância às firmas com maior participação de mercado, às expensas das firmas menores. SLADE (1986), salienta, contudo, que a escolha dos pesos deve ser feita cautelosamente, dado que as elasticidades podem ser sensíveis à escolha efetuada. O presente trabalho usou o número de freqüências de vôo como pesos, conforme será discutido na próxima seção.
} 


\subsubsection{Jogo de Preços}

Uma vez assumidas as condições de demanda, sobretudo no que diz respeito à diferenciação de produto, parte-se para a modelagem da rivalidade entre as firmas. Considere um mercado oligopolístico de transporte aéreo com competição estática em preços e jogadas simultâneas, como em BERRY et alii (2006). ${ }^{18}$ O uso dos preços como variável estratégica é procedimento padrão em caso de mercados com produto heterogêneo; além disso, tem-se que, como descrito anteriormente, desde a Segunda Rodada de Desregulamentação, tem sido observada no setor a ocorrência de episódios "guerras de preços", o que fortalece a tese de que a competição é pautada por movimentos dessa variável. ${ }^{19}$

Tem-se, assim, que o problema da firma neste mercado pode ser resumido pela seguinte condição de primeira ordem (CPO) para maximização de lucros.

$$
\max _{P_{i}}\left(p_{i} q_{i}-t c_{i}\right) \longrightarrow q_{i}+p_{i} \frac{\partial q_{i}}{\partial p_{i}}-\frac{\partial t c_{i}}{\partial q_{i}} \frac{\partial q_{i}}{\partial p_{i}}
$$

Onde $q_{i}, p_{i}$ e $t c_{i}$ são, respectivamente, a quantidade demandada, o preço e o custo total da firma $i$; por meio de manipulação, pode-se chegar a:

$$
q_{i}+p_{i} q_{i}^{\prime}-m c_{i} q_{i}^{\prime}=0 \longrightarrow m r_{i}=\frac{1}{q_{i}^{\prime}} q_{i}+p_{i}=m c_{i}
$$

Onde $m r_{i}$ e $m c_{i}$ são, respectivamente, a receita marginal e o custo marginal da firma $i$ e $q_{i}$ ' é a primeira derivada em preços da função demanda (1). Assim, por meio de manipulação adicional, obtém-se a seguinte equação de preços, associada à condição de primeira ordem para maximização de lucros (CPO) da firma:

$$
p_{i}=m c_{i}-\frac{1}{q_{i}^{\prime}} q_{i}
$$

A expressão em (5) reflete o comportamento esperado das firmas caso estejam em situação de equilíbrio não-cooperativo. Uma outra forma de pensar o problema pode ser em termos das chamadas "variações conjeturais". o termo $q_{i}^{\prime}=d q_{i} / d p_{i}$ pode ser analisado considerando-se que a firma $i$ possui crenças, conjeturas, sobre a forma na qual as firmas oponentes variam seus preços, caso ela própria varie seu preço. Essas crenças são denominadas de "variações conjeturais", e são definidas matematicamente por $\lambda_{i}=d p_{i}^{-} / d p_{i}$, termo que emerge a partir do seguinte desenvolvimento:

$$
q_{i}^{\prime}=\frac{d q_{i}}{d p_{i}}=\frac{\partial q_{i}}{\partial p_{i}}+\frac{d q_{i}}{d p_{i}^{-}} \frac{d p_{i}^{-}}{d p_{i}}
$$

No caso da demanda linear, tem-se que:

$$
q_{i}^{\prime}=\beta_{1}+\beta_{2} \frac{d p_{i}^{-}}{d p_{i}}=\beta_{1}+\beta_{2} \lambda_{1}
$$

Onde $\lambda_{i}$ mede as conjecturas da firma $i$ em relação ao oponente médio. Assim, quando $\lambda_{i}=0$, tem-se a hipótese clássica de variações conjeturais nulas em preços de Bertrand, que resultaria em preço igual ao custo marginal caso estivéssemos em um mercado com produto homogêneo. Como os consumidores percebem as firmas como distintas - há, portanto, diferenciação de produtos na forma

\footnotetext{
${ }^{18}$ Em contraposição a MARÍN (1995) e BRANDER e ZHANG (1990), que assumem competição estática em quantidades. BRANDER e ZHANG (1993) constitui-se em uma das poucas tentativas encontradas na literatura de se modelar um mercado dinâmico de transporte aéreo.

${ }^{19} \mathrm{Em}$ extensões ao presente modelo, poder-se-ía utilizar também as seguintes variáveis estratégicas: número de freqüências de vôos e gastos com propaganda.
} 
expressa em (1) -, essa conjetura, correspondente ao chamado oligopólio tomador de preços (pricetaking), não leva ao resultado de competição perfeita, ${ }^{20}$ mas sim a preços superiores ao custo marginal e no patamar do equilíbrio de Nash (referencial de equilíbrio não-cooperativo); tem-se, portanto, que a firma que age como tomadora de preços possui poder de mercado devido à diferenciação de produtos. A CPO, nesse caso, pode ser expressa como:

$$
p_{i}=m c_{i}-\frac{1}{\beta_{1}} q_{i}, \lambda_{i}=0
$$

Por outro lado, caso $\lambda_{i}=1$, tem-se que as firmas adotam um comportamento conhecido na literatura como equiparador de preços (price matching), também conhecido como estratégia de "cobertura de preço", isto é, a firma mimetiza qualquer variação em preços das concorrentes, alterando também seus preços - inclusive, muitas vezes tornando esse comportamento um compromisso público. Tanto a literatura de economia quanto de marketing costuma enquadrar essa prática como colusiva e anti-competitiva; por exemplo, segundo SALOP (1986), tal conduta sinaliza à concorrência para que mantenha elevados seus preços, evitando reduções para capturar fatia de mercado, por meio da ameaça de corte semelhante nos preços. A manutenção do preço colusivo torna-se, nesse caso, estratégia ótima para cada firma e o preço se sustenta acima do nível representado pelo equilíbrio não-cooperativo (CORTS, 1995). Na prática, entretanto, considera-se que, quanto maior o parâmetro de conduta das companhias, maior é a probabilidade de que elas estejam empreendendo alguma prática colusiva, seja de "equiparador de preços" ou não, e, portanto, o referencial $\lambda_{i}=1$ acaba por fornecer uma relevante ferramenta de análise antitruste, sendo usado com essa finalidade no presente trabalho (referencial de conduta colusiva). ${ }^{21}$

A expressão (8) abaixo mostra o formato da CPO no caso de equiparação de preços:

$$
p_{i}=m c_{i}-\frac{1}{\beta_{1}+\beta_{2}} q_{i}, \lambda_{i}=1
$$

\section{ESTIMAÇÃO DA CONDUTA DAS COMPANHIAS AÉREAS}

\subsection{Estimação em Duas Etapas e Bootstrapping}

A prática consolidada em Organização Industrial requer que se utilize algum método de equações simultâneas na estimação de um sistema de demanda e oferta como o formado pelas expressões (1) e (4). Essa estimação pode ser feita em um único procedimento econométrico, considerando-se o sistema como um todo, ou pode ser feita em etapas, equação-por-equação. ${ }^{22} \mathrm{Em}$ geral, o segundo método é preferível pelo fato de evitar que potenciais problemas em uma equação influenciem as estimações $\mathrm{da}(\mathrm{s})$ outra(s) equações do sistema; como coloca SLADE (2004): "An advantage of a two-step procedure is that misspecification of the first-order condition does not contaminate the demand estimates, in which one typically has more confidence". De fato, tem-se que, na maioria dos casos, o analista tem maior capacidade de observação do lado da demanda - e até alguma intuição com relação à matriz de elasticidades-preço e ao posicionamento das marcas no mercado -, do que do lado da oferta, onde o custo marginal, implícito em (4), é não-observável na maioria dos casos.

\footnotetext{
${ }^{20}$ Que, se o produto fosse homogêneo, representaria o chamado "Paradoxo de Bertrand". Note que o termo "price-taking" é, em geral, associado apenas ao caso de produto homogêneo. Diferentemente, em SLADE (1986), ele é mais abrangente e significa o resultado de mercado obtido adotando-se variações conjeturais nulas, seja em mercados com produto homogêneo ou diferenciado. Esta definição mais abrangente é adotada pelo presente trabalho.

${ }^{21}$ Aliás, tem-se que o conceito de "equiparação de preços" reflete precisamente um comportamento colusivo de movimentações simultâneas de preços, ideal para o estudo de caso aqui proposto.

${ }^{22}$ Esses métodos de estimação de equações simultâneas são conhecidos como métodos de informação limitada (ou de equação única), em contraposição aos métodos de informação completa (ou de sistema).
} 
O presente trabalho buscou, portanto, lidar com um estimador em duas etapas, Two-Step Estimator, como em NEVO (2001), PETRIN e TRAIN (2002), SLADE (2004) e ASKER (2004) e CHINTAGUNTA e DESIRAJU (2005); para uma descrição do bootstrap no âmbito de estimação de demanda e oferta em Organização Industrial, ver HUSE e SALVO (2005); para uma abordagem alternativa, utilizando-se um estimador de sistema, com aplicação à mesma base de dados, vide OLIVEIRA (2005). No presente artigo, tem-se que, na primeira etapa, é efetuada a estimação da demanda (1), para, na segunda etapa, proceder-se com a estimação da CPO em (4), uma vez conhecidos os parâmetros de demanda aplicáveis. Esse procedimento pode ser feito de duas formas: primeiramente, desconsiderando o fato de que alguns dos parâmetros da segunda etapa foram estimados na etapa anterior, o que leva a tratá-los como valores determinísticos, ao invés de variáveis aleatórias. Nesta abordagem, a CPO seria estimada da seguinte forma:

$$
p_{i}=m c_{i}\left(\chi_{i}\right)-\delta_{i} q_{i}+\varepsilon_{i}
$$

Onde $\chi_{i}$ são deslocadores de custo marginal, e $\varepsilon_{i}$ são os resíduos. Inferir acerca da conduta, neste contexto, significa simplesmente testar possíveis valores para $\delta_{i}$, ou, em outras palavras, impor restrições sobre $\delta_{i}$ e testar a significância destas restrições; estas restrições aos valores de $\delta_{i}$ estão diretamente ligadas às restrições em $\lambda_{i}$ descritas em 3.3.2. Em particular, se $\delta_{i}=1 / \hat{\beta}_{1}$, tem-se o equilíbrio de Bertrand-Nash, ou seja, o oligopólio tomador de preços $\left(\hat{\lambda}_{1}=0\right)$; e se $\delta_{i}=1 /\left(\hat{\beta}_{1}+\hat{\beta}_{2}\right)$, tem-se o oligopólio equiparador de preços $\left(\hat{\lambda}_{1}=1\right)$.

Saindo do mundo das variações conjeturais, pode-se, ainda com a equação (9), testar se a firma em questão pratica a conduta de precificação ao custo marginal; neste caso, a firma não detém (ou joga como se não detivesse) poder de mercado algum. Este teste de hipótese é simples, podendo ser configurado como $H_{0}: \delta_{i}=0$.

Entretanto, o procedimento acima é falho ao não computar a aleatoriedade adicional, no contexto do teste de hipóteses, engendrada por $\hat{\beta}_{1}$ e $\hat{\beta}_{2}$, pelo fato destes serem coeficientes estimados previamente, e não os verdadeiros parâmetros populacionais. Naturalmente, uma segunda forma de abordagem seria o tratamento efetivo de $\hat{\beta}_{1}$ e $\hat{\beta}_{2}$ enquanto estimativas, o que implicaria na necessidade de desenvolvimento analítico de testes de hipóteses quanto a restrições não-determinísticas nos parâmetros. Estes testes de hipóteses seriam equivalentes a testes de igualdade das médias amostrais de duas variáveis aleatórias, sob condições de desconhecimento das variâncias populacionais. A desvantagem desse procedimento é, em geral, devido à maior complexidade gerada pela formulação de estatísticas e a discussão das propriedades assintóticas das distribuições decorrentes.

Uma abordagem considerada intermediária às duas acima listadas, e que, ao mesmo tempo, não desconsidera o fato que $\hat{\beta}_{1}$ e $\hat{\beta}_{2}$ foram obtidos em uma etapa anterior da estimação, bem como não exige o desenvolvimento de formulação analítica para o teste de hipóteses e, portanto, para o problema da inferência estatística quanto ao comportamento do oligopólio, é o uso de bootstrap. Com esta técnica, é possível desenvolver um modelo empírico contendo variáveis estimadas em etapas anteriores - como visto, contexto típico do Two-Step Estimator - dado que é feita a correção dos desvios padrões dessas variáveis. Para maiores detalhes sobre como o bootstrap opera, vide breve exposição no Apêndice 1 a este trabalho.

Assim, no contexto da estimação em duas etapas aqui proposta, a técnica de bootstrap não-paramétrico foi utilizada como forma de considerar o caráter de estimativa, não determinístico, dos coeficientes de demanda, obtidos na primeira etapa da estimação do modelo, e que estão presentes nas CPO. Os desvios-padrões corrigidos dessa forma são aqui chamados de Two-Step Consistent (TSC).

A configuração do estimador em um contexto de bootstrap é feita da forma a seguir. Considere a seguinte transformação em $q_{i}$ :

$$
q_{i}^{m}=\frac{1}{\hat{\beta}_{1}} q_{i}
$$


Assume-se que transformação acima gera uma variável aleatória que é função de um coeficiente de demanda, obtido em estimação prévia. Justamente por esse motivo, o uso de $q_{i}^{m}$, ao invés de $q_{i}$, na estimação da CPO em (9), enseja uso de bootstrap na correção dos desvios padrões da estimativa do seu coeficiente. Apesar de necessitar de um procedimento estatístico adicional, ou seja, do procedimento de bootstrap, a inclusão da transformação (10) em (9) possui a seguinte vantagem: ela simplifica o teste de hipóteses associado ao Equilíbrio de Bertrand-Nash (oligopólio tomador de preços) de $H_{0}: \delta=1 / \hat{\beta}_{1}$ para $H_{0}: \delta=1$, na seguinte expressão:

$$
p_{i}=m c_{i}\left(\chi_{i}\right)-\delta_{i} q_{i}^{m}+\varepsilon_{i}
$$

Desta forma, basta um simples teste quanto à imposição de restrição determinística em $\delta_{i}$ na expressão (11) para se efetuar o teste da conduta do oligopólio; é importante notar que este teste é realizado utilizando-se os desvios padrões das estimativas de $\delta_{i}$, já corrigidos por bootstrapping.

Importante salientar que, antes de cada rodada de estimação das CPO's com as pseudo-amostras (bootstrap não-paramétrico), é necessário proceder com a estimação da equação de demanda correspondente; este procedimento foi aqui adotado e permite a obtenção de um valor $\hat{\beta}_{1}(b)-$ e, por decorrência, um valor $q_{i}^{m}(b)^{23}$ - para cada CPO estimada, o que é mais adequado em termos de consideração da variabilidade adicional proporcionada pelo uso de uma variável aleatória como regressor. Este $\hat{\beta}_{1}(b)$ deve, preferencialmente, ser extraído aleatoriamente de uma distribuição normal com média $\mu_{\hat{\beta}_{1}}$ e variância $\sigma_{\hat{\beta}_{1}}^{2}$, ambos parâmetros previamente obtidos por meio da estimação da equação de demanda; tem-se, assim, a combinação de um procedimento de bootstrap não-paramétrico com um de bootstrap paramétrico.

No caso de teste da conduta de "equiparação de preços" do oligopólio, adota-se, ao invés de (10), a seguinte transformação em $q_{i}$ :

$$
q_{i}^{m}=\frac{1}{\hat{\beta}_{1}+\hat{\beta}_{2}} q_{i}
$$

Igualmente, testar se a firma i adotou este tipo de conduta colusiva, é apenas um teste simples da restrição (determinística) $\delta_{i}=1$, na expressão (11). Da mesma forma que (11), aqui também cabe, antes de estimar as CPO's para cada pseudo-amostra bootstrap, estimar primeiro a demanda correspondente e extrair aleatoriamente valores de $\hat{\beta}_{1}$ e $\hat{\beta}_{2}$.

Em suma, uma vez feitas as transformações (10) ou (12), em conjunto com a correção dos desvios padrões dos coeficientes estimados de $q_{i}^{m}$, é possível então promover o teste das condutas do oligopólio, em um procedimento que é Two-Step Consistent (TSC) - dado que considera o caráter aleatório das estimativas prévias de demanda, como geradores de variabilidade adicional aos parâmetros estimados da CPO.

\subsection{Base de Dados e Modelagem Empírica}

A base de dados disponível para a estimação da modelagem empírica, equivalente ao arcabouço teórico detalhado em 3.3 e 4.1, foi fornecida pelo Departamento de Aviação Civil (informações publicadas e não-publicadas), e coletadas entre outubro de 2001 e janeiro de 2002. Os dados estão dispostos na forma de painel (cross-section com séries temporais), no período de janeiro de 1997 a setembro de 2001, para as companhias aéreas Varig, Rio-Sul, TAM, Vasp e Transbrasil. ${ }^{24}$ O mercado é considerado na forma direcional, de forma que os dados compreendem informação tanto do par-de-aerportos Congonhas-Santos

\footnotetext{
${ }^{23}$ Onde b é o indicador da b-ésima pseudo-amostra, vide Apêndice 1.

${ }^{24}$ A base de dados compreende 57 pontos para cada firma em cada par-de-aeroporto direcional. A única exceção é a Transbrasil, que saiu do mercado em junho de 2000 , por ocasião do acordo code-share com a Tam, e, portanto tem 41 pontos amostrais; para fins de análise, o período de curta re-entrada da Transbrasil no mercado, em 2001, não foi considerado.
} 
Dumont quanto Santos Dumont-Congonhas. Ao todo, foi obtida uma amostra com 538 observações para a estimação do modelo.

O equivalente empírico do sistema de equações (1) e (4) está apresentado abaixo. A equação de demanda (1) é estimada na seguinte forma:

$$
\begin{aligned}
q_{i t}= & \beta_{0}+\beta_{1} p i t+\beta_{2} p_{i t}^{-}+\beta_{3} f_{i t}+\beta_{4} f_{i t}^{-}+\beta_{5} p i b_{t}+\beta_{6} q p d a_{t}^{-} \\
& +\sum_{u} \kappa_{1 u} d c i a_{u}+\sum_{v} \sum_{u} \kappa_{2 v u} d c s h_{v} d c i a_{u}+\sum_{w} \kappa_{3 e w} d t r i m_{w}+\sum_{y} \kappa_{4 y} d s a z_{y}+\varepsilon_{i t}
\end{aligned}
$$

Onde $q_{i t}$ é o número de passageiros transportados pagos da cia aérea $i$, no mês $t$, extraídos de relatórios (não publicados) de tráfego de origem e destino mensais do DAC. ${ }^{25} p_{i t}$ é uma média ponderada dos preços da companhia aérea $i$, no mês $t$, ajustada pela inflação (IPCA/IBGE) até janeiro de 2002; as estruturas de tarifas das firmas foram coletadas a cada dia 15 no sistema histórico ATPCO ${ }^{26}$; os pesos foram construídos utilizando-se o número de assentos oferecidos, nos respectivos meses, durante o "pico" (tarifa cheia) e "fora do pico" (média aritmética dos descontos), considerando-se "pico" todos os vôos de dias-de-semana dentro dos intervalos 05:00-10:00 e 16:30-22:00.

$p_{i t}^{-}$é uma média ponderada dos preços médios das companhias rivais - o "oponente médio" da firma $i$ na Ponte Aérea; os pesos foram construídos utilizando-se o número de freqüências de vôo oferecidas por cada companhia aérea. Seguindo a recomendação de SLADE (1986), foi feita uma análise de sensibilidade utilizando-se pesos alternativos na construção de $p_{i t}^{-}$, como o número de assentos oferecidos e o número de passageiros transportados por companhia aérea, sem alteração significativa nos resultados do modelo.

As variáveis $f_{i t}$ e $f_{i t}^{-}$representam, respectivamente, o número de freqüências de vôo da companhia aérea $i$ e do "oponente médio" desta firma, no mês $t$; tal informação foi extraída dos relatórios HOTRAN (Horários de Transporte) do DAC. As freqüências do "oponente médio" foram construídas dividindo-se o número total de freqüências das companhias rivais pelo número de companhias rivais. Espera-se que quanto maior a presença da companhia aérea na oferta da ligação $\left(f_{i}\right)$, dada a presença do oponente médio $\left(f_{i}^{-}\right)$, maior seja a sua demanda; o inverso também é esperado, ou seja, deslocamentos das freqüências das rivais atuem, ceteris paribus, como redutores de demanda da firma $i$.

pib $_{t}$ é um índice do produto interno bruto (a preços de mercado, do Sistema de Contas Nacionais ${ }^{27}$ ); $q p d a_{t}^{-}$é o número de passageiros transportados nos demais pares-de-aeroportos entre Rio de Janeiro e São Paulo, o que constituiria uma proxy para o efeito competitivo destas ligações sobre a ligação Congonhas-Santos Dumont; dcia controla os efeitos específicos das companhias aéreas ${ }^{28}$; $d c s h$ controla os efeitos dos períodos de acordos code-share (pool da Ponte Aérea, acordo Vasp-Transbrasil e acordo TAM-Transbrasil), na demanda de cada uma das firmas; $d$ trim controla o efeito temporal, contado de forma trimestral; $d s a z$ controla os efeitos de sazonalidade ao longo de um ano (dummies para os meses do ano); por fim, os $\beta$ 's e $\kappa$ 's são parâmetros e $\varepsilon_{i t}$ são os resíduos.

A condição de primeira-ordem empírica proposta, equivalente a (4), é a seguinte:

\footnotetext{
${ }^{25}$ Para se inferir o número de passageiros que seriam transportados na ligação Congonhas-Santos Dumont durante o período em que o aeroporto Santos Dumont ficou fechado devido ao incêndio de fevereiro de 1998, utilizou-se o número de passageiros incremental na ligação Congonhas-Galeão - esta ligação era praticamente inexistente antes do incêndio em Santos Dumont e passou a apresentar volumes consideráveis após o incidente. Este procedimento de data filling foi realizado para o período entre fevereiro e julho de 1998.

${ }^{26}$ Airline Tariff Publishing Company.

${ }^{27}$ Série de elaboração do IPEA, obtida na base de dados Ipeadata (www. ipeadata.gov . br).

${ }^{28}$ Para fins de montagem do painel, desagregou-se cada firma em duas partes, uma operando cada par-de-aeroporto direcional, gerando, assim, um efeito fixo para a ida e para a volta, específico para cada companhia aérea. Assim, $u=1, \ldots, 2 N$, onde $N$ é o número de companhias aéreas operando na ligação.
} 


$$
\begin{aligned}
p_{i t}= & \gamma_{0}+\gamma_{1} \text { combustível }_{i t}+\gamma_{2} \text { tripulação }_{i t}+\gamma_{3} \text { manutenção }_{i t}+\gamma_{4} f_{i t} \\
& +\delta_{1} q_{i t}+\delta_{2} q_{i t} d l i b 98+\delta_{3} q_{i t} d u s 99+\delta_{4} q_{i t} d \text { coord } 99+\delta_{5} q_{i t} d r e a j 00 \\
& +\delta_{6} q_{i t} d g o / 01+\sum_{u} \phi_{u} q_{i t} d c i a_{u}+\sum_{u} \varphi_{1 u} d c i a_{u}+\sum_{v} \sum_{u} \varphi_{2 v u} d c s h_{v} d c i a_{u} \\
& +\sum_{w} \varphi_{3 w} \text { dtrim }_{w}+\sum_{y} \varphi_{3 y} d s a z_{y}+\xi_{i t}
\end{aligned}
$$

Pelo lado do custo marginal, tem-se, em (14), os seguintes deslocadores: combustível ${ }_{i t}$ é uma proxy para o preço unitário do insumo combustível, calculada dividindo-se as despesas totais mensais com combustível (querosene de aviação) pelo total de litros consumidos; tripulação ${ }_{i t}$ é uma proxy para o preço unitário do insumo trabalho, calculada dividindo-se as despesas com salários da tripulação pelo número de horas voadas; já manutenção ${ }_{i t}$ reflete os custos unitários com manutenção de aeronaves, calculados por meio da divisão das despesas com manutenção pelo total de horas voadas. Os dados de custos foram obtidos em relatórios econômicos mensais (não-publicados) do DAC e os valores foram corrigidos pelo IPA/FGV.

É importante salientar que, para os dados de custos, foi possível obter uma desagregação mensal por tipo de aeronave das companhias aéreas, ao invés da agregação tradicional ao nível do sistema (total da malha), também constante dos anuários do DAC. Dessa forma, os valores mencionados acima, referemse apenas ao tipo de avião operado por cada companhia aérea na ligação sob análise, ${ }^{29}$ o que contribuiu para se obter variáveis deslocadoras de custos que fossem mais próximas da realidade daquele mercado em específico. $f_{i t}$ e $q_{i t}$ refletem, como visto, o número de vôos realizados na ligação, ${ }^{30}$ e o número de passageiros transportados pela companhia $i$, em um dado mês $t$.

Já pelo lado da conduta, tem-se que dlib98, dus99, dcoord99, dreaj00 e dgol01 são variáveis binárias deslocadoras do coeficiente da variável $q_{i}$, e, portanto, da conduta competitiva, construídas à luz dos "eventos relevantes", discutidos na sub-seção 3.2. Assim, elas representam as variações na conduta devidas, respectivamente, ao período posterior à Segunda Rodada de Liberalização (construída de forma once and for all, a partir de janeiro de 1998 até o final da amostra), a desvalorização cambial de 1999 (compreendendo o período de janeiro de 1999 até julho de 2000, mês anterior ao reajuste de preços de 2000), ao período de suposta coordenação de preços entre as companhias aéreas (entre agosto e dezembro de $1999^{31}$ ), ao período posterior ao reajuste concedido pelo DAC, em 2000 (também construído como once and for all, a partir de agosto daquele ano), e ao período de descontos praticados nos meses imediatamente subseqüentes à entrada da Gol no Galeão, em 2001 (de fevereiro a maio de 2001); os $\gamma$ 's, $\delta$ 's, $\phi$ 's, e $\varphi$ 's são parâmetros e $\xi_{i t}$ são resíduos.

Considerando-se as transformações propostas em 4.1, onde $q_{i}$ é substituído por $q_{i}^{m}$, tem-se a seguinte expressão da CPO empírica final:

\footnotetext{
${ }^{29}$ Para a Tam, as aeronaves no período amostral eram o Fokker 100 e o Airbus A319; para Varig, Transbrasil e Vasp, o B737-300, e para a Rio-Sul (em operação conjunta com a Varig), também o ERJ-145 e o B737-500, além do B737-300.

${ }^{30}$ Por um lado, mais vôos, dada a demanda, tende a fazer aumentar o custo marginal (os vôos saem mais vazios e há menor diluição de custos fixos por passageiro); por outro, mais vôos permitem uma maior diluição de custos fixos por vôo, o que pode contribuir para reduzir preços e elevar a demanda (arrefecendo a diluição por passageiro). O sinal de $f_{i}$ é, portanto, indeterminado ex-ante.

${ }^{31}$ Em janeiro de 2000, a Vasp divulgou a concessão de descontos de uma promoção "meio-a-meio" em vários mercados, dentre eles, a Ponte Aérea. Isso caracterizou o fim de um suposto período colusivo, iniciado em agosto de 1999, justificando esta configuração de dcoord99.
} 


$$
\begin{aligned}
p_{i t}= & \gamma_{0}+\gamma_{1} \text { combustível }_{i t}+\gamma_{2} \text { tripulação }_{i t}+\gamma_{3} \text { manutenção }_{i t}+\gamma_{4} f_{i t} \\
& +\delta_{1} q_{i t}^{m}+\delta_{2} q_{i t}^{m} \text { dlib98 }+\delta_{3} q_{i t}^{m} d u s 99+\delta_{4} q_{i t}^{m} \text { dcoord } 99+\delta_{5} q_{i t}^{m} d r e a j 00 \\
& +\delta_{6} q_{i t}^{m} d g o l 01+\sum_{u} \phi_{u} q_{i t}^{m} d c i a_{u}+\sum_{u} \varphi_{1 u} d c i a_{u}+\sum_{v} \sum_{u} \varphi_{2 v u} d c s h_{v} d c i a_{u} \\
& +\sum_{w} \varphi_{3 w} \text { dtrim }_{w}+\sum_{y} \varphi_{3 y} d_{s a z_{y}}+\xi_{i t}
\end{aligned}
$$

\begin{tabular}{|c|c|c|c|c|c|}
\hline \multirow[t]{2}{*}{ Variáveis } & \multirow[t]{2}{*}{ Descrição } & \multicolumn{4}{|c|}{ Estatiistísticas } \\
\hline & & Média & DesvPad & Min & Máx \\
\hline$q_{i t}$ & Número de Passageiros da Cia Aérea $i$ & $24,619.3$ & $16,034.5$ & $4,037.0$ & $71,641.0$ \\
\hline$p_{i t}$ & Preço da Cia Aérea $i$ & 161.0 & 41.3 & 76.2 & 267.7 \\
\hline$p_{i t}^{-}$ & $\begin{array}{l}\text { Preço Médio das Oponentes da Cia Aé- } \\
\text { rea } i\end{array}$ & 161.6 & 31.3 & 115.4 & 243.8 \\
\hline$f_{i t}$ & $\begin{array}{l}\text { Número de Frequências de Vôo Men- } \\
\text { sais da Cia Aérea } i\end{array}$ & 413.8 & 316.0 & 70.4 & $1,736.0$ \\
\hline$f_{i t}^{-}$ & $\begin{array}{l}\text { Número de Frequências Médias das } \\
\text { Oponentes da Cia Aérea } i\end{array}$ & 405.2 & 166.8 & 142.0 & 964.3 \\
\hline$p i b_{t}$ & $\begin{array}{l}\text { Índice de atividade econômica (Jan } \\
1997=100)\end{array}$ & 108.3 & 4.8 & 97.9 & 117.8 \\
\hline$q p d a_{t}^{-}$ & $\begin{array}{l}\text { Número de Passageiros nos demais } \\
\text { pares-de-aeroporto da ligação }\end{array}$ & $32,377.4$ & $8,192.1$ & $19,769.0$ & $57,600.0$ \\
\hline combustível $_{i t}$ & $\begin{array}{l}\text { Custo Unitário - Combustível da Cia } \\
\text { Aérea i }\end{array}$ & 530.0 & 183.5 & 263.0 & $1,270.6$ \\
\hline tripulação $_{i t}$ & $\begin{array}{l}\text { Custo Unitário - Tripulação da Cia Aé- } \\
\text { rea } i\end{array}$ & $1,173.1$ & 347.0 & 521.1 & $2,076.0$ \\
\hline manutenção $_{i t}$ & $\begin{array}{l}\text { Custo Unitário - Arrendamento de Ae- } \\
\text { ronaves da Cia Aérea } i\end{array}$ & $1,060.2$ & 466.4 & 303.9 & $3,334.1$ \\
\hline
\end{tabular}

Estatísticas descritivas das principais variáveis de demanda e oferta estão apresentadas na Tabela 3.

Tabela 3 - Estatísticas Descritivas

\subsection{Estimador, Endogeneidade e Instrumentos}

O método de estimação utilizado foi o MMG (Método dos Momentos Generalizado. ${ }^{32}$ ) Este estimador possui ganhos de eficiência com relação aos métodos usuais de estimação de equações simultâneas, como o 2SLS, por ser robusto à presença de padrão de heteroscedasticidade de forma desconhecida. ${ }^{33}$ Como em (13) e (15) são controlados os efeitos dos indivíduos (companhia aérea e code-shares) e do tempo (trimestres e sazonalidade), obtém-se resultados equivalentes ao estimador de efeitos fixos para painéis de dados.

Foram consideradas $q_{i}\left(\mathrm{e} q_{i}^{m}\right), p_{i}$, e $p_{i}^{-}$como variáveis endógenas no modelo. As variáveis $f_{i}$ e $f_{i}^{-}$foram tratadas como exógenas por dois motivos: primeiro, devido à política regulatória no que tange à concessão de linhas aéreas, que, mesmo tendo sido flexibilizada com a desregulamentação

\footnotetext{
${ }^{32}$ Software utilizado na estimação: Stata v. 8.2.

${ }^{33}$ Não é possível e nem relevante tratar autocorrelação, entretanto, dado que o procedimento de bootstrap é, por natureza, um procedimento de reamostragem que, em última instância, descaracteriza a ordenação dos dados no tempo.
} 
dos anos 1990, ainda não permitia total liberdade de ajuste do número de freqüências de vôo, no curto prazo, pelas companhias aéreas; segundo porque os aeroportos envolvidos são dos mais congestionados do País (inclusive com regra de slots), o que impede aumentos das freqüências de vôo em resposta a condições competitivas. Um teste $C$, de exogeneidade/ortogonalidade de instrumentos incluídos (Teste de Sargan-em-diferenças), realizado especificamente em $f_{i}$ e $f_{i}^{-}$, foi realizado, obtendo-se um valor de 1,044 ( -value $=0,593$ ), não sendo possível rejeitar a hipótese de que essas variáveis são, efetivamente, exógenas. ${ }^{34}$

Foram utilizadas como variáveis instrumentais de preços, na equação de demanda, o deslocador de custos unitários do combustível (Varig), bem como um índice de taxa de câmbio efetiva mensal (US\$, IPA-OG - exportações, ${ }^{35}$ ) defasado de um período; além disso, foram utilizados os preços próprios e do oponente médio praticados pelas companhias em uma outra ligação doméstica (Congonhas - Brasília); foram também utilizados atributos (número de frequência de vôo) de algumas companhias aéreas na ligação Pampulha-Brasília (Varig e Vasp). O procedimento de utilizar preços de outros mercados como instrumentos é utilizado por HAUSMAN et alii (1994) e é válido quando não há existência de choques comuns de demanda em ambos os mercados. ${ }^{36}$ No caso da equação de CPO, foi utilizado o procedimento sugerido por BERRY et alii (1995), na geração dos instrumentos: utilizou-se características das firmas oponentes, no caso, as frequências de rivais na ligação Pampulha-Brasília; também foi utilizada uma dummy representativa do período de incêndio em Santos Dumont.

Em ambos os casos (equações de demanda e CPO), foram realizados testes de validade e relevância dos instrumentos acima descritos, basicamente os testes J de Hansen, de sobre-identificação e orthogonalidade dos instrumentos propostos e testes LR de Correlação Canônica de Anderson. Foram obtidos os seguintes resultados: demanda com estatística J de 2,023 ( $p$-value $=0,732$ ) e estatística de Anderson de 43,848 ( $p$-value $=0.001$ ); CPO com estatística J de 1,336 ( $p$-value de 0,248) e estatística de Anderson de 25,788 ( $p$-value de 0,001); Os testes J de Hansen possibilitaram inferir não ser possível rejeitar a hipótese nula de que os instrumentos são válidos - isto é, ortogonais ao vetor de resíduos -, e os testes de Anderson permitiram rejeitar a hipótese nula de que os modelo está subidentificado.

Em termos de relevância dos instrumentos escolhidos, calculou-se a estatística $\mathrm{F}$, de significância conjunta dos instrumentos no primeiro estágio das regressões, obtendo-se, tanto para demanda quanto para a CPO, e para todas as variáveis endógenas, valores F sempre acima de 10, o que está de acordo com a regra de STAIGER e STOCK (1997) para afastar o problema de "instrumentos fracos".

Em conjunto aos testes gerais de validade dos instrumentos, foram realizados testes específicos com relação às variáveis de preços em outros mercados, sugeridas por HAUSMAN et alii (1994). Mais uma vez, um teste $C$, de exogeneidade/ortogonalidade, desta vez quanto a instrumentos excluídos, foi gerado especificamente para se verificar a qualidade destes instrumentos. Obteve-se uma estatística calculada de 3,821 ( $p$-value $=0,148$ ), não sendo possível rejeitar a hipótese nula de que essas variáveis são, efetivamente, ortogonais. Foi também realizado um teste de redundância de instrumentos específicos (HALL e PEIXE, 2000), também para essas variáveis, obtendo-se o valor de 27,015 ( $p$-value $=0,00002$ ), rejeitando-se a nula de que os instrumentos são redundantes. Todos esses testes são indicativos da validade e relevância dos instrumentos sugeridos pelos autores, o que por si só já é uma constatação importante para pesquisas aplicadas em geral, dado que o uso de variáveis instrumentais na identificação da demanda é um ponto nevrálgico e polêmico na literatura.

\footnotetext{
${ }^{34}$ Foi também testada a exogeneidade das variáveis deslocadoras de custos na CPO, não se rejeitando a hipótese nula em nenhum dos casos.

${ }^{35}$ Fonte: Instituto de Pesquisa Econômica Aplicada (IPEA), obtido no website http: //www . ipeadata . gov . br .

${ }^{36}$ Por exemplo, choques devidos a propaganda em nível nacional. Vide abaixo uma descrição dos resultados dos testes efetuados quanto a ortogonalidade e a relevância dos instrumentos.
} 


\subsection{Resultados}

Os resultados das estimações das equações (13) e (15) encontram-se apresentados nas Tabelas 4 e 5 abaixo. Primeiramente, a equação de demanda:

\begin{tabular}{|c|c|}
\hline Variáveis Explicativas & $q_{i t}$ \\
\hline$p_{i t}$ & $\begin{array}{r}-158.6 \ddagger \\
(33.8)\end{array}$ \\
\hline$p_{i t}^{-}$ & $\begin{array}{r}122.4 \ddagger \\
(38.7)\end{array}$ \\
\hline$f_{i t}$ & $\begin{array}{r}12.4 \ddagger \\
(2.2)\end{array}$ \\
\hline$f_{i t}^{-}$ & $\begin{array}{r}-9.6 \ddagger \\
(3.3)\end{array}$ \\
\hline$p i b_{t}$ & $\begin{array}{r}564.9 \ddagger \\
(168.6)\end{array}$ \\
\hline$q p d a_{t}^{-}$ & $\begin{array}{l}-0.012 \\
(0.036)\end{array}$ \\
\hline constante & $\begin{array}{r}-39066 \dagger \\
(19704)\end{array}$ \\
\hline № Observações & 538 \\
\hline Centered R2 & 0.952 \\
\hline$F(55,482)$ & $281.99 \ddagger$ \\
\hline Estatística J Hansen & 2.023 \\
\hline Estatística LR de Anderson & $43.848 \ddagger$ \\
\hline
\end{tabular}

Notas: Desvios Padrões HC em parênteses. Dummies controladoras de efeitos (companhia aérea, acordos code-share, trimestres e sazonalidade) omitidas. (*) Significante a 10\%; (†) Significante a 5\%; (†) Significante a 1\%.

Em seguida, na Tabela 5, com as estimações da CPO, são reportados os resultados alcançados sem (coluna 1) e com as transformações em $q_{i t}\left(q_{i t}^{m}\right)$, sugeridas na seção anterior, conforme as expressões (10) e (12). Dispostas, respectivamente, nas colunas (2) e (3), estas estimações são indicativas dos resultados referentes ao oligopólio tomador de preços e equiparador de preços, como visto anteriormente:

Em primeiro lugar, pode-se notar, na Tabela 4, que, pelo lado da demanda, como a maioria dos coeficientes são bastante significativos e possuem os sinais coerentes com a expectativa $a$ priori da teoria econômica. Notadamente, a ligação é bastante sensível às variações no PIB, relação esta esperada exante, visto se tratar de um mercado com características de viagens a negócios (executivos de empresas, profissionais liberais, etc). De fato, a elasticidade-renda (PIB) da demanda estimada ficou em torno de 3,90 . Isso não significa que a variável preço não tenha poder explicativo na geração de tráfego, como costuma colocar o senso comum. Pelo contrário, tanto as variáveis $p_{i t}$ quanto $p_{i t}^{-}$mostraram-se altamente significativas, refletindo uma elasticidade-preço própria estimada de $-1,68$ e cruzada de $1,29 .^{37}$

A outra variável explicativa, $f_{i t}$, representativa das freqüências da companhia aérea $i$ na ligação, mostrou-se, também, como esperado, muito relevante enquanto indicador de vantagem competitiva

\footnotetext{
${ }^{37}$ Tanto a elasticidade-renda como as elasticidades-preço da demanda aqui reportadas são médias amostrais das elasticidades estimadas. Assim, os valores foram calculados extraindo-se a elasticidade em cada ponto amostral e obtendo-se a média das elasticidades de todos os pontos do painel de dados. Note que as elasticidades-preço ao nível da firma costumam ser bem maiores que a elasticidade-preço do mercado. OLIVEIRA (2005), por exemplo, estima a elasticidade-preço deste mesmo mercado agregado em -0,3, não obstante chegar a estimativas da elasticidade-preço própria (compensada), mensurada ao nível da firma, em torno de $-2,0$.
} 
Tabela 5 - Resultados da Estimação - Equação de Preços

\begin{tabular}{|c|c|c|c|}
\hline Variável Dependente & $\begin{array}{l}\text { (1) Sem Transforma- } \\
\text { ção } p_{i t}\end{array}$ & $\begin{array}{ll}(2) & \text { Transformação } \\
q_{i t}^{m} & \text { Tomador de } \\
\text { Preços } p_{i t} & \\
\end{array}$ & $\begin{array}{l}\text { (3) Transformação } \\
q_{i t}^{m} \quad \text { Equiparador de } \\
\text { Preços } p_{i t} \\
\end{array}$ \\
\hline combustível $_{i t}$ & $\begin{array}{l}0.033 \ddagger \\
(0.009)\end{array}$ & $\begin{array}{l}0.033 \ddagger \\
(0.012)\end{array}$ & $\begin{array}{l}0.033 \ddagger \\
(0.012)\end{array}$ \\
\hline tripulaçãa $_{i t}$ & $\begin{array}{l}0.025 \ddagger \\
(0.006)\end{array}$ & $\begin{array}{l}0.027 \ddagger \\
(0.007)\end{array}$ & $\begin{array}{l}0.027 \ddagger \\
(0.007)\end{array}$ \\
\hline manutenção $_{i t}$ & $\begin{array}{l}0.001 \\
(0.002)\end{array}$ & $\begin{array}{l}-0.001 \\
(0.003)\end{array}$ & $\begin{array}{l}-0.001 \\
(0.003)\end{array}$ \\
\hline$f_{i t}$ & $\begin{array}{l}-0.007 \\
(0.007)\end{array}$ & $\begin{array}{l}-0.011 \\
(0.009)\end{array}$ & $\begin{array}{l}-0.011 \\
(0.009)\end{array}$ \\
\hline$q_{i t}^{m}$ & $\begin{array}{l}0.005 \dagger \\
(0.002)\end{array}$ & $\begin{array}{l}0.967 \\
(0.618)\end{array}$ & $\begin{array}{l}0.221 \\
(0.472)\end{array}$ \\
\hline$q_{i t}^{m} \mathrm{x} d t b a$ & $\begin{array}{l}-0.002 \ddagger \\
(0.001)\end{array}$ & $\begin{array}{l}-0.462 \\
(0.312)\end{array}$ & $\begin{array}{l}-0.106 \\
(0.225)\end{array}$ \\
\hline$q_{i t}^{m} \mathrm{x} d t a m$ & $\begin{array}{l}-0.004 \ddagger \\
(0.001)\end{array}$ & $\begin{array}{l}-0.725 * \\
(0.420)\end{array}$ & $\begin{array}{l}-0.166 \\
(0.345)\end{array}$ \\
\hline$q_{i t}^{m} \mathrm{x} d v s p$ & $\begin{array}{l}-0.004 \ddagger \\
(0.001)\end{array}$ & $\begin{array}{l}-0.749 * \\
(0.404)\end{array}$ & $\begin{array}{l}-0.171 \\
(0.352)\end{array}$ \\
\hline$q_{i t}^{m} \mathrm{x} d r s l$ & $\begin{array}{l}-0.003 \ddagger \\
(0.001)\end{array}$ & $\begin{array}{l}-0.463 \\
(0.334)\end{array}$ & $\begin{array}{l}-0.106 \\
(0.242)\end{array}$ \\
\hline$q_{i t}^{m} \mathrm{x} d l i b 98$ & $\begin{array}{l}-0.002 \ddagger \\
(0.000)\end{array}$ & $\begin{array}{l}-0.310 \dagger \\
(0.138)\end{array}$ & $\begin{array}{l}-0.071 \\
(0.138)\end{array}$ \\
\hline$q_{i t}^{m} \mathbf{x} d u s 99$ & $\begin{array}{l}-0.003 \ddagger \\
(0.001)\end{array}$ & $\begin{array}{l}-0.5722^{*} \\
(0.311)\end{array}$ & $\begin{array}{l}-0.131 \\
(0.265)\end{array}$ \\
\hline$q_{i t}^{m} \mathrm{x} d$ coord 99 & $\begin{array}{l}0.001^{*} \\
(0.001)\end{array}$ & $\begin{array}{l}-0.041 \\
(0.032)\end{array}$ & $\begin{array}{l}-0.009 \\
(0.021)\end{array}$ \\
\hline$q_{i t}^{m} \mathrm{x} d r e a j 00$ & $\begin{array}{l}-0.002 \dagger \\
(0.001)\end{array}$ & $\begin{array}{l}-0.500 * \\
(0.293)\end{array}$ & $\begin{array}{l}-0.114 \\
(0.235)\end{array}$ \\
\hline$q_{i t}^{m} \mathrm{x} d g o l 01$ & $\begin{array}{l}0.001 \ddagger \\
(0.001)\end{array}$ & $\begin{array}{l}-0.050^{*} \\
(0.029)\end{array}$ & $\begin{array}{l}-0.012 \\
(0.024)\end{array}$ \\
\hline constante & $\begin{array}{l}127.174 \ddagger \\
(10.395)\end{array}$ & $\begin{array}{l}123.393 \ddagger \\
(12.714)\end{array}$ & $\begin{array}{l}123.393 \ddagger \\
(12.369)\end{array}$ \\
\hline № Observações & 538 & & \\
\hline R2 Centralizado & 0.788 & & \\
\hline$F(64,473)$ & $57.46 \ddagger$ & & \\
\hline Estatística J Hansen & 2.030 & & \\
\hline Estatística LR de Anderson & $13.404 \dagger$ & & \\
\hline
\end{tabular}

Notas: Desvios Padrões HC e TSC em parênteses. * Significante a $10 \%$; $†$ Significante a 5\%; e $\ddagger$ Significante a $1 \%$. Dummies controladoras de efeitos (companhia aérea, acordos code-sharing, trimestres e sazonalidade) omitidas. $d t b a, d t a m, d v s p$ e $d r s l$ são as dummies de efeitos das firmas, deslocadoras de $q_{i t}^{m}(d c i a)$. 
neste mercado com produto diferenciado. Em conjunto, $f_{i t}$ e $f_{i t}^{-}$permitem controlar o fato de que companhias aéreas que têm aumentado o seu número de freqüências de vôo, dadas as freqüências das rivais, têm aumentada a sua probabilidade de captura dos passageiros mais sensíveis ao horário, pela redução de seu tempo médio de espera ${ }^{38}$; esse fenômeno é ainda mais relevante em se tratando de um mercado shuttle. Na verdade, conforme discutido na seção anterior, as assimetrias na dominância das freqüências constituem-se no maior fator de diferenciação de produto neste mercado, o que é capturado por essas variáveis. Já $q d p a^{-}$teve sinal esperado mas não significativo.

Pelo lado do custo marginal (parte superior das condições de primeira ordem, na Tabela 5), logrou-se estimar alguns coeficientes cujos sinais foram condizentes com o esperado e significativos - as variáveis proxy para combustível e tripulação. Também, o uso das dummies de firma, acordo code-sharing, trimestre e sazonalidade (efeitos controláveis em painéis de dados, mas não apresentados na Tabela 3) garante que fatores de custos mensurados inadequadamente ou não-observáveis, sejam incluídos e reduzam os potenciais vieses na estimação pelo lado da conduta. Ainda tratando do custo marginal, tem-se que o coeficiente da variável $f_{i}$ é negativo, mas não significativo.

Por fim, tem-se a análise da conduta, realizada por meio de um estudo dos coeficientes de $q_{i}^{m}$ e de suas dummies deslocadoras. A partir dessa análise, tem-se base para efetuar algumas inferências antitruste, conforme é o objeto deste trabalho. Isso será realizado na próxima seção. Antes disso, contudo, é importante tecer comentários sobre os desvios padrões corrigidos por bootstrap para o caso de equiparador de preços (coluna (3) da Tabela 5). Como pode ser visto nesta coluna, quase nenhum dos coeficientes relativos a $q_{i}^{m}$, naquela coluna, é significantemente diferente de zero, o que é explicado pelo forte incremento nos desvios padrões promovido pela correção bootstrap; isto era esperado, dada a aleatoriedade adicional acarretada pela introdução de $\hat{\beta}_{2}$ em (11) via (12), mas também é indicativo de que o modelo colusivo não tem poder explicativo razoável com relação ao processo gerador dos dados.

\subsection{Análise dos Parâmetros de Conduta e Inferências de Poder de Mercado}

Uma vez conduzida a estimação do modelo empírico, pode-se imediatamente realizar os testes de hipótese acerca das condutas de oligopólio tomador de preços (não-cooperativa) e equiparador de preços (colusiva). Essa análise permite fazer, em última instância, inferências sobre o exercício de poder de mercado, dentro de uma abordagem antitruste estrutural, e, no caso, com relação ao episódio de aumento de preços de agosto de 1999.

As Tabelas 6, 7 e 8, a seguir, apresentam os testes de hipótese com relação ao comportamento das firmas no mercado. Nelas, são apresentados os valores dos parâmetros de $q_{i}$ ou $q_{i}^{m}$, estimados tanto para o Caso-Base (período anterior à Segunda Rodada de Liberação, abrangendo 1997), como para o período posterior a cada um dos eventos relevantes descritos na Seção 3.2, e que são potencialmente deslocadores de conduta: medidas de desregulamentação de 1997-98 (controlado por dlib98), desvalorização cambial de 1999 (dus99), aumento de preços de agosto de 1999 (dcoord99), aumento de preços de 2000 (dreaj00), reações à entrada da Gol no Galeão e pressões da alta do dólar naquele ano ( $d g o l 01)$. Como pode ser observado nas tabelas, a análise da conduta foi desagregada ao nível da firma (Varig, Rio Sul, TAM, Vasp e Transbrasil).

Primeiramente, a Tabela 6 apresenta os testes de conduta de precificação ao custo marginal (hipótese nula $H_{0}: \delta_{i}=0$ ), equivalentes à coluna (1) da Tabela 5:

A Tabela 7, abaixo, apresenta os testes de conduta de tomador de preço (hipótese nula $H_{0}: \delta_{i}=1$ ), levando em conta a transformação $q_{i t}^{m}$ em (10), referentes à coluna (2) da Tabela 5:

Por fim, a Tabela 8 apresenta os testes de conduta de equiparador de preço (também com hipótese nula $H_{0}: \delta_{i}=1$ ), levando em conta a transformação $q_{i t}^{m}$ em (12), e referentes à coluna (3) da Tabela 5:

A interpretação das Tabelas 6, 7 e 8, permite fazer inferências sobre o comportamento competitivo das firmas no mercado. Uma análise antitruste das tabelas permite concluir que, para a quase totalidade

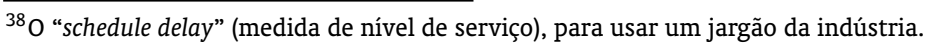


Tabela 6 - Teste de Precificação ao Custo Marginal (CPO sem Transformação)

\begin{tabular}{|l|l|r|r|r|r|r|}
\hline Período & Eventos Relevantes & VRG & RSL & TAM & VSP & TBA \\
\hline Jan/97 - & (0) Pré 2a. Rodada de & $0.468 \dagger$ & $0.901 \ddagger$ & $0.094 \mathrm{NR}$ & $0.065 \mathrm{NR}$ & $0.238^{*}$ \\
Dez/97 & Liberalização, 1997 (Caso & $(0.192)$ & $(0.295)$ & $(0.088)$ & $(0.108)$ & $(0.127)$ \\
& & & & & \\
& Base) & & & & \\
\hline Jan/98 - & (1) Liberalização, Incên- & $0.289^{*}$ & $0.202^{*}$ & $-0.085 \mathrm{NR}$ & $-0.114 \mathrm{NR}$ & $0.058 \mathrm{NR}$ \\
Dez/98 & dio e Reabertura de SDU, & $(0.157)$ & $(0.112)$ & $(0.055)$ & $(0.074)$ & $(0.094)$ \\
& Fim do "Pool"(dlib98) & & & & & \\
\hline Jan/99 - & (2) Desvalorização Cam- & $0.182^{*}$ & $-0.084 \dagger$ & $-0.192 \ddagger$ & $-0.221 \ddagger$ & $-0.049 \mathrm{NR}$ \\
Jul/00 & bial de 1999 (dus99) & $(0.095)$ & $(0.035)$ & $(0.033)$ & $(0.028)$ & $(0.040)$ \\
\hline Ago/99 - & (3) Período sob Investiga- & $0.160^{*}$ & $-0.105 \ddagger$ & $-0.213 \ddagger$ & $-0.243 \ddagger$ & $-0.0697^{*}$ \\
Dez/99 & ção Antitruste (coord99) & $(0.090)$ & $(0.035)$ & $(0.034)$ & $(0.028)$ & $(0.040)$ \\
\hline Ago/00 - & (4) Reajuste de Preços de & $0.227 \dagger$ & $-0.039 \mathrm{NR}$ & $-0.147 \ddagger$ & $-0.176 \ddagger$ & $-0.003 \mathrm{NR}$ \\
Out/01 & Agosto de 2000 (dreaj00) & $(0.097)$ & $(0.035)$ & $(0.031)$ & $(0.030)$ & $(0.043)$ \\
\hline Fev/01 - & (5) Entrada da Gol & $0.435 \dagger$ & $0.170 \mathrm{NR}$ & $0.062 \mathrm{NR}$ & $0.032 \mathrm{NR}$ & $0.205 \mathrm{NR}$ \\
Mai/01 & em GIG, alta do dólar & $(0.194)$ & $(0.114)$ & $(0.090)$ & $(0.110)$ & $(0.129)$ \\
& (dgol01) & & & & & \\
\hline
\end{tabular}

Notas: Estimativas e desvios padrões foram multiplicados por 100. Teste acerca da hipótese do coeficiente de $q_{i}$ (somado ao coeficiente de uma interação com dummy, quando for o caso) ser igual a zero. Desvios Padrões em parênteses. (*) Significante a 10\%; (†) Significante a 5\%; e (†) Significante a 1\%. NR representa a não-rejeição da hipótese, aos três níveis de significância mencionados.

Tabela 7 - Teste de Conduta de Tomador de Preços (CPO com Transformação 1)

\begin{tabular}{|c|c|c|c|c|c|c|}
\hline Período & Eventos Relevantes & VRG & RSL & TAM & VSP & TBA \\
\hline $\begin{array}{l}\text { Jan/97 - } \\
\operatorname{Dez} / 97\end{array}$ & $\begin{array}{l}\text { (0) Pré 2a. Rodada de } \\
\text { Liberalização, } 1997 \text { (Caso } \\
\text { Base) }\end{array}$ & $\begin{array}{r}-0.033 \mathrm{NR} \\
(0.618)\end{array}$ & $\begin{array}{r}-1.023 \dagger \\
(0.402)\end{array}$ & $\begin{array}{r}-0.758 \ddagger \\
(0.229)\end{array}$ & $\begin{array}{r}-0.782 \ddagger \\
(0.265)\end{array}$ & $\begin{array}{r}-0.496 \mathrm{NR} \\
(0.344)\end{array}$ \\
\hline $\begin{array}{l}\text { Jan/98 - } \\
\operatorname{Dez} / 98\end{array}$ & $\begin{array}{l}\text { (1) Liberalização, Incên- } \\
\text { dio e Reabertura de SDU, } \\
\text { Fim do "Pool” (dlib98) }\end{array}$ & $\begin{array}{r}-0.344 \mathrm{NR} \\
(0.499)\end{array}$ & $\begin{array}{r}-0.497 \mathrm{NR} \\
(0.321)\end{array}$ & $\begin{aligned}-1.068 \ddagger \\
(0.147)\end{aligned}$ & $\begin{array}{r}-1.092 \ddagger \\
(0.188)\end{array}$ & $\begin{aligned}-0.806 \ddagger \\
(0.236)\end{aligned}$ \\
\hline $\begin{array}{l}\text { Jan/99 - } \\
\text { Jul/00 }\end{array}$ & $\begin{array}{l}\text { (2) Desvalorização Cam- } \\
\text { bial de } 1999 \text { (dus99) }\end{array}$ & $\begin{array}{l}-0.605^{*} \\
(0.326)\end{array}$ & $\begin{array}{r}-1.069 \ddagger \\
(0.080)\end{array}$ & $\begin{array}{r}-1.330 \ddagger \\
(0.130)\end{array}$ & $\begin{array}{r}-1.354 \ddagger \\
(0.137)\end{array}$ & $\begin{aligned}-1.068 \ddagger \\
(0.094)\end{aligned}$ \\
\hline $\begin{array}{l}\text { Ago/99 - } \\
\text { Dez/99 }\end{array}$ & $\begin{array}{l}\text { (3) Período sob Investiga- } \\
\text { ção Antitruste (coord99) }\end{array}$ & $\begin{array}{r}-0.646 \dagger \\
(0.304)\end{array}$ & $\begin{array}{r}-1.110 \ddagger \\
(0.088)\end{array}$ & $\begin{array}{r}-1.371 \ddagger \\
(0.149)\end{array}$ & $\begin{array}{r}-1.395 \ddagger \\
(0.153)\end{array}$ & $\begin{array}{r}-1.1088 \ddagger \\
(0.096)\end{array}$ \\
\hline $\begin{array}{l}\text { Ago/00 - } \\
\text { Out/01 }\end{array}$ & $\begin{array}{l}\text { (4) Reajuste de Preços de } \\
\text { Agosto de } 2000 \text { (dreaj00) }\end{array}$ & $\begin{array}{r}-0.534 \mathrm{NR} \\
(0.342)\end{array}$ & $\begin{array}{r}-0.997 \ddagger \\
(0.079)\end{array}$ & $\begin{array}{r}-1.258 \ddagger \\
(0.107)\end{array}$ & $\begin{array}{r}-1.282 \ddagger \\
(0.117)\end{array}$ & $\begin{aligned}-0.996 \ddagger \\
(0.096)\end{aligned}$ \\
\hline $\begin{array}{l}\text { Fev/01 - } \\
\text { Mai/01 }\end{array}$ & $\begin{array}{l}\text { (5) Entrada da Gol } \\
\text { em GIG, alta do dólar } \\
\text { (dgol01) }\end{array}$ & $\begin{array}{r}-0.084 \mathrm{NR} \\
(0.613)\end{array}$ & $\begin{array}{r}-0.547^{*} \\
(0.317)\end{array}$ & $\begin{array}{r}-0.808 \ddagger \\
(0.229)\end{array}$ & $\begin{array}{r}-0.832 \ddagger \\
(0.267)\end{array}$ & $\begin{array}{r}-0.546 \mathrm{NR} \\
(0.341)\end{array}$ \\
\hline
\end{tabular}

Notas: Teste acerca da hipótese do coeficiente de $q_{i}^{m}$ (somado ao coeficiente de uma interação com dummy, quando for o caso) ser igual a um. Desvios Padrões em parênteses. (*) Significante a 10\%; (†) Significante a 5\%; e ( $)$ Significante a 1\%. NR representa a não-rejeição da hipótese, aos três níveis de significância mencionados. 
Tabela 8 - Teste de Conduta de Equiparador de Preços (CPO com Transformação 2)

\begin{tabular}{|l|l|r|r|r|r|r|}
\hline Período & Eventos Relevantes & VRG & RSL & TAM & VSP & TBA \\
\hline Jan/97 - & (0) Pré 2a. Rodada de & $-0.779 *$ & $-1.005 \ddagger$ & $-0.945 \ddagger$ & $-0.950 \ddagger$ & $-0.885 \ddagger$ \\
Dez/97 & Liberalização, 1997 (Caso & $(0.472)$ & $(0.170)$ & $(0.138)$ & $(0.142)$ & $(0.256)$ \\
& Base) & & & & & \\
\hline Jan/98- & (1) Liberalização, Incên- & $-0.850 \dagger$ & $-0.885 \ddagger$ & $-1.016 \ddagger$ & $-1.021 \ddagger$ & $-0.956 \ddagger$ \\
Dez/98 & dio e Reabertura de SDU, & $(0.341)$ & $(0.238)$ & $(0.070)$ & $(0.092)$ & $(0.132)$ \\
& Fim do "Pool"(dlib98) & & & & & \\
\hline Jan/99- & (2) Desvalorização Cam- & $-0.910 \ddagger$ & $-1.016 \ddagger$ & $-1.075 \ddagger$ & $-1.081 \ddagger$ & $-1.015 \ddagger$ \\
Jul/00 & bial de 1999 (dus99) & $(0.213)$ & $(0.054)$ & $(0.145)$ & $(0.158)$ & $(0.047)$ \\
\hline Ago/99- & (3) Período sob Investiga- & $-0.919 \ddagger$ & $-1.025 \ddagger$ & $-1.085 \ddagger$ & $-1.090 \ddagger$ & $-1.0248 \ddagger$ \\
Dez/99 & ção Antitruste (coord99) & $(0.194)$ & $(0.067)$ & $(0.163)$ & $(0.175)$ & $(0.056)$ \\
\hline Ago/00- & (4) Reajuste de Preços de & $-0.893 \ddagger$ & $-0.999 \ddagger$ & $-1.059 \ddagger$ & $-1.065 \ddagger$ & $-0.999 \ddagger$ \\
Out/01 & Agosto de 2000 (dreaj00) & $(0.241)$ & $(0.038)$ & $(0.113)$ & $(0.126)$ & $(0.044)$ \\
\hline Fev/01 - & (5) Entrada da Gol & $-0.791 *$ & $-0.897 \ddagger$ & $-0.956 \ddagger$ & $-0.962 \ddagger$ & $-0.896 \ddagger$ \\
Mai/01 & em GIG, alta do dólar & $(0.453)$ & $(0.220)$ & $(0.124)$ & $(0.131)$ & $(0.238)$ \\
& (dgol01) & & & & & \\
\hline
\end{tabular}

Notas: Teste acerca da hipótese do coeficiente de $q_{i}^{m}$ (somado ao coeficiente de uma interação com dummy, quando for o caso) ser igual a um. Desvios Padrões em parênteses. (*) Significante a 10\%; ( $\dagger$ ) Significante a 5\%; e ( $)$ Significante a 1\%. NR representa a não-rejeição da hipótese, aos três níveis de significância mencionados.

dos casos, é possível rejeitar, aos níveis de significância de 1\%,5\% e 10\%, a hipótese de que as firmas praticaram conduta de cobertura (equiparação) de preços em algum momento no período amostral; isso é constatado diretamente pelos resultados da Tabela 8. Além disso, é possível rejeitar, nas mesmas bases e para todas as firmas envolvidas, essa forma de comportamento colusivo no período específico sob investigação, ou seja, aquele imediatamente posterior ao aumento de preços de agosto de 1999.

Assim, pode-se afirmar que, independentemente de questões de coordenação de preço terem sido discutidas na reunião dos dirigentes das companhias aéreas na semana anterior ao aumento de preços em tela, esta mesma reunião, bem como o próprio aumento em si, muito provavelmente não produziram efeitos no mercado, em termos de prática de colusão - neste caso, do tipo equiparação de preços. Pelo contrário, os testes foram indicativos de condutas competitivas ou super-competitivas, dependendo do caso. Por exemplo, enquanto há fortes evidências de que a Varig manteve conduta não-cooperativa do tipo tomador de preços (Bertrand-Nash) por quase todo o período, os dados mostram também claramente que tanto TAM, Vasp e Transbrasil adotaram conduta exacerbadamente competitiva, com casos de precificação ao custo marginal ou até abaixo dele - situações estas onde os coeficientes estimados tiveram sinal negativo, e houve rejeição das hipóteses nulas, em todas as tabelas (ex. TAM e Vasp entre 1999 e 2000).

A explicação para a conduta super-competitiva acima descrita, e observada a partir da Segunda Rodada de Liberalização de 1997-98, é diferente caso se trate de TAM ou se trate do par Vasp-Transbrasil. Enquanto que, no primeiro caso (TAM), buscava-se uma estratégia de "comprar mercado", 39 ou seja, conquistar fatia de mercado ao custo da lucratividade, no segundo caso (Vasp), tratava-se de problemas gerados a partir de dificuldades de adaptação ao novo ambiente desregulamentado e mais competitivo,

\footnotetext{
${ }^{39}$ o que levou a firma a ter o maior crescimento de market-share na ligação. O resultado de estratégias de "compra de mercado" é similar ao da predação, ou seja, visa aumentar (ou manter) a participação no mercado independentemente da lucratividade a curto prazo; sendo assim, a firma adota um jogo dinâmico onde desconsidera o seu poder de mercado no curto prazo, para auferir lucratividade no longo prazo. O modelo de competição proposto neste artigo pode ser considerado uma forma reduzida deste modelo dinâmico.
} 
com o fim do pool da Ponte Aérea - problemas de gestão que levaram, em última instância, à saída tanto da Vasp como da Transbrasil da indústria. Como forma de corroborar esses resultados, basta uma breve análise na evolução da lucratividade das firmas neste mercado (vide Figura no Apêndice 2), de onde se extrai a informação de que tais firmas passaram de patamares de $40 \%$ de resultado operacional anual, em 1996, para prejuízos elevados e constantes a partir de 1998.

A evolução conduta estimada da Rio-Sul é mais intrigante. Uma análise das tabelas mostra que esta empresa teve sua competitividade em muito incrementada com a liberalização. Entretanto, uma investigação na Figura do Apêndice 2, tem-se que a lucratividade da Rio-Sul, reportada no Anuário Estatístico do DAC, seguiu de perto a lucratividade da Varig, firma à qual se aliou, neste mercado, a partir de agosto de 1998 (Ponte Varig-Rio Sul). Os resultados parecem ilustrar dois pontos: 1) que mesmo firmas em code-share podem apresentar situações competitivas distintas, dependendo de suas operações, custos e posicionamento no mercado; e 2) que informações a partir de análises do lucro contábil podem ser bem diferentes das embasadas no lucro econômico. ${ }^{40}$

A principal conclusão do exercício de aplicação da abordagem NOIE a essa importante ligação do transporte aéreo nacional é que as movimentações paralelas de preços de agosto de 1999 não acarretaram efeitos relevantes sobre o mercado, tendo representado muito provavelmente apenas uma tentativa de realinhamento de receitas unitárias em face ao choque cambial do início daquele ano, não tendo sido capazes de representar um efetivo distanciamento de referenciais competitivos no mercado. $\mathbf{O}$ modelo permite, portanto, concluir que, a coordenação de preços, alegada pelas autoridades antitruste, muito provavelmente não levou à instauração de condutas colusivas nesta ligação.

Por fim, cabe fazer uma menção a respeito de possíveis padrões de liderança neste mercado: FARINA (2004) sugere este tipo de configuração, mas de uma forma um pouco mais sofisticada do que usualmente é encontrado em literatura: poderia estar acontecendo alternância no possível papel de "líder" entre Varig e TAM, e que nem os modelos típicos de liderança de preços e nem os modelos que não assumem esta hipótese, seriam apropriados para descrever a real conduta competitiva das firmas no mercado. Entretanto, uma análise dos resultados das Tabelas 6, 7 e 8, mostra que a suposição de existência de uma firma líder fica comprometida pelo fato de não se conseguir rejeitar, em todo o período amostral, os padrões não-cooperativos de conduta (seja Bertrand-Nash, precificação ao custo marginal ou abaixo dele) para nenhuma dessas empresas; para que houvesse liderança de preços, deveria ser observado tanto Varig como TAM se alternando com práticas de equiparação de preços, enquanto as demais jogariam como tomadoras de preço - hipóteses que foram rejeitadas pelas análises empíricas. Assim, torna-se questionável a argumentação de que existe liderança quando não há firmas exercitando seu poder de mercado por conta desse possível status.

\section{CONCLUSÕES}

Buscou-se efetuar, no presente trabalho, uma investigação antitruste da conduta das companhias aéreas no mercado constituído pela Ponte Aérea Rio de Janeiro - São Paulo. Tal análise foi motivada pela abertura de inquérito pela Secretaria de Direito Econômico em março de 2000, em razão do aumento coordenado de dez por cento nos preços na ligação, dias após a imprensa ter divulgado a realização de uma reunião entre os seus principais empresários.

Procurou-se construir um Modelo de Parâmetro de Conduta no estilo da abordagem da Nova Organização Industrial Empírica, NOIE, com vistas a se analisar a competição neste mercado, e as variações nos mark-ups preço-custo devido a eventos relevantes, como a desvalorização cambial de 1999, ou a entrada da Gol no Aeroporto Galeão, em 2001. O parâmetro de conduta estimado foi comparado com valores referenciais teóricos representativos do equilíbrio de Nash e precificação ao custo marginal, além de um padrão típico de comportamento colusivo, de "equiparador de preços" (conhecido como "cobertura de

\footnotetext{
${ }^{40}$ No caso, o lucro contábil aponta para alta lucratividade, enquanto que a análise econômica aponta para mark-ups baixos ou negativos. Custos fixos não são observáveis para o analista, entretanto.
} 
preços"). Uma importante contribuição metodológica foi a implementação de rotinas de bootstrapping para a correção dos desvios padrões das estimativas da conduta, dentro de um arcabouço econométrico de Two-Step Estimator (como sugerido, em Organização Industrial, por SLADE 2004).

As conclusões obtidas apontaram para a rejeição da hipótese de que as empresas estavam em conluio do tipo equiparação de preços, bem como não foi possível rejeitar hipóteses de situações competitivas, seja do Equilíbrio de Bertrand-Nash, seja situações de precificação ao nível do custo marginal ou abaixo dele. Nesse sentido, é possível argumentar que, mesmo sob o ponto de vista legal, as empresas não causaram infração à ordem econômica, como coloca o artigo 20, incisos III e IV, da Lei de Defesa da Concorrência: "aumentar arbitrariamente os lucros" e "exercer de forma abusiva posição dominante".

Há que se salientar, contudo, que as conclusões do presente trabalho não significam que as autoridades de defesa da concorrência não tenham outras razões legais para promover o inquérito, dado que as evidências da reunião prévia entre os empresários e da simultaneidade das ações podem ser consideradas como tentativa de prejudicar a livre concorrência, o que é exposto no artigo 20 , inciso I, daquela lei. A possível utilização de um sistema de intercâmbio de informações extra-preço poderia ser apontada como evidência adicional de infração, como consta do argumento da SEAE. Procurou-se demonstrar, entretanto, que esses fatores, isoladamente considerados, não tiveram eficácia para propiciar uma conduta prejudicial ao bem-estar econômico líquido no mercado, por meio de colusão ou prática de cartel.

A discussão mais importante que o trabalho buscou realizar, entretanto, diz respeito à contribuição para uma metodologia de análise de processos antitruste, que tem se firmado como instrumentos de intervenção importantes no que tange ao monitoramento de mercados oligopolísticos recentemente liberalizados - caso do transporte aéreo brasileiro na atualidade. Busca enfatizar, inclusive, que à recémcriada agência reguladora do setor (ANAC), dentro de um novo marco regulatório, devem ser assegurados instrumentos ativos que permitam o desempenho das tarefas de monitoramento antitruste nesta indústria, em conjunto com as instituições já designadas para a defesa da concorrência por lei, como o CADE, a SDE e a SEAE. Deve-se salientar, contudo, a relevante restrição de que, ao se configurar a nova agência, evite-se acarretar problemas de coordenação com os órgãos antitruste existentes, caso contrário, a eficiência econômica poderá ser penalizada na forma de um aumento indesejado nos custos de transação.

Agradecimentos Os autores gostariam de agradecer a colaboração de Michael Waterson, Margaret Slade, Elizabeth Farina, Milton Valdir Feitosa, Adalberto Febeliano, Jorge Silveira, Clarisse Rodrigues, Robson Ramos, Allemander Pereira Filho, do Departamento de Aviação Civil, dos participantes da sessão de Transporte Aéreo do Congresso da Associação Nacional de Pesquisa e Ensino em Transportes (Campinas, 2001) e do congresso da Royal Economic Society (Coventry, 2003), dos dois pareceristas anônimos, e o apoio da CAPES e FAPESP. Agradecimentos especiais a Rachel Oliveira. Os autores são responsáveis por eventuais erros e omissões.

\section{Referências Bibliográficas}

(2001). Processo Administrativo - Conduta Varig, Tam, Transbrasil e Vasp. Secretaria de Acompanhamento Econômico. Parecer MF - COGDC-DF, No. 363.

ANDRADE, T. (2004). Voto-vista de conselheiro. processo administrativo n. 08012.000677/1999-70. Conselho Administrativo de Defesa Econômica.

ASKER, J. (2004). Measuring cost advantages from exclusive dealing: An empirical study of beer distribution. Technical report, Dept. of Economics, Harvard University. 
BERECHMAN, J. \& SHY, O. (1996). The structure of airline equilibrium networks. In Bergh, J., Nijkamp, P., \& Rietveld, P., editors, Recent Advances in Spatial Equilibrium: Methodologies and Applications. SpringerVerlag, Berlin.

BERRY, S. (1990). Airport presence as product differentiation. American Economic Review, 80:394-399.

BERRY, S., CARNALL, M., \& SPILLER, P. (2006). Airline hubs: Costs, markups and the implications of customer heterogeneity. In LEE, D., editor, Competition Policy and Antritrust, volume I of Advances in Airline Economics, pages 297-328. Elsevier, Cambridge, USA.

BERRY, S., LEVINSOHN, J., \& PAKES, A. (1995). Automobile prices in market equilibrium. Econometrica, 63:841-890.

BOGUSLASKI, R., ITO, H., \& LEE, D. (2004). Entry patterns in the southwest airlines route system. Review of Industrial Organization, 25:317-350.

BORENSTEIN, S. (1989). Hubs and high fares: Dominance and market power in the U.s. airline industry. Rand Journal of Economics, 20:344-365.

BORENSTEIN, S. (1991). The dominant-firm advantage in multiproduct industries: Evidence form the U.s. airlines. Quarterly Journal of Economics, 106:1237-1266.

BRANDER, J. \& ZHANG, A. (1990). Market conduct in the airline industry: An empirical investigation. Rand Journal of Economics, 21:567-583.

BRANDER, J. \& ZHANG, A. (1993). Dynamic oligopoly behaviour in the airline industry. International Journal of Industrial Organization, 11:407-435.

BRESNAHAN, T. (1989). Empirical studies of industries with market power. In Schmalensee, R. \& Willig, R., editors, Handbook of Industrial Organization. Elsevier Science Publishers, Amsterdam.

BURNHAM, K. P. (2004). Notes of class. Disponível em http://www.warnercnr.colostate.edu/ class_info/fw663/bootstrap.pdf.

CHINTAGUNTA, P. \& DESIRAJU, R. (2005). Strategic pricing and detailing behavior in international markets. Marketing Science, 24:67-80.

CORTS, K. (1995). On the robustness of the argument that price-matching is anti-competitive. Economics Letters, 47:417-421.

DAVISON, A. C. \& HINKLEY, D. V. (1997). Bootstrap Methods and Their Application. Cambridge University Press, Cambridge.

EFRON, B. (1979). Bootstrap methods: another look at the jackknife. Annals of Statistics, 7:1-26.

EFRON, B. \& TIBSHIRANI, R. J. (1993). An Introduction to the Bootstrap. Chapman and Hall, New York.

EVANS, W. \& KESSIDES, I. (1993). Localized market power in the U.s. airline industry. Review of Economics and Statistics, 75:66-75.

EVANS, W. \& KESSIDES, I. (1994). Living by the "golden rule": Multimarket contact in the U.s. airline industry. Quarterly Journal of Economics, 109:341-366.

FARINA, E. (2004). Voto-vista de conselheiro. processo administrativo n. 08012.000677/1999-70.

FORGIONI, P. A. (1998). Os fundamentos do antitruste. 
GENESOVE, D. \& MULLIN, W. (1998). Testing static oligopoly models: Conduct and cost in the sugar industry, 1890-1914. Rand Journal of Economics, 29:355-377.

GEROSKI, P. (1988). In pursuit of monopoly power: Recent quantitative work in industrial economics. Journal of Applied Econometrics, 3:107-123.

GREEN, E. \& PORTER, R. (1984). Noncooperative collusion under imperfect price information. Econometrica, 52:87-100.

HAIR, J. F., ANDERSON, R. E., Tatham, R. L., \& Black, W. C. (1998). Multivariate Data Analysis. Upper Saddle River: Prentice-Hall, 5 edition.

HALL, A. R. \& PEIXE, F. P. M. A. (2000). Consistent method for the selection of relevant instruments. In Econometric Society World Congress Contributed Papers.

HAUSMAN, J., LEONARD, G., \& ZONA, D. (1994). Competitive analysis with differentiated products. Annales d'Economie et de Statistique, 34:159-180.

HUSE, C. \& SALVO, A. (2005). Métodos empíricos em organização industrial e aplicações ao antitruste. In Seminário Estudos em Métodos Quantitativos Aplicados a Defesa da Concorrência e a Regulação Econômica. SDE, IPEA, ANPEC, Brasília.

KARACA-MANDIC, P. \& TRAIN, K. (2003). Standard error correction in two-stage estimation with nested samples. Econometrics Journal, 6:401-407.

LEVINE, M. (1987). Airline competition in deregulated markets: Theory, firm strategy, and public policy. Yale Journal on Regulation, 4:393-494.

MARÍN, P. (1995). Competition in european aviation: Pricing policy and market structure. Journal of Industrial Economics, 43:141-159.

MAS-COLELL, A., WHINSTON, M., \& GREEN, J. (1995). Microeconomic Theory. Oxford University Press, New York.

MELLO, M. T. L. (2002). Defesa da concorrência. In KUPFER, D. \& HASENCLEVER, L., editors, Economia Industrial: Fundamentos Teóricos e Práticas no Brasil. Editora Campus, Rio de Janeiro.

NEVO, A. (2001). Measuring market power in the ready-to-eat cereal industry. Econometrica, 69:307-342.

OLIVEIRA, A. V. M. (2005). The impacts of liberalization on competition on an air shuttle market. In Proceedings of the 32nd Conference of the European Association of Research in Industrial Economics EARIE.

OLIVEIRA, A. V. M. (2006). Estimation of a model of low cost carrier entry: Evidence from brazil. In LEE, D., editor, Advances in Airline Economics, Competition Policy and Antritrust, volume I, pages 297-328. Elsevier, Cambridge, USA.

OLIVEIRA, A. V. M. \& HUSE, C. (2004). Localized competitive advantage and price reactions to low cost carrier entry in the brazilian airline industry. In Proceedings of the 2004 Air Transport Research Society (ATRS) World Conference.

OLIVEIRA, G. (2001). Concorrência: Panorama no Brasil e no Mundo. Editora Saraiva, São Paulo.

PARK, J. (1997). The effects of airline alliances on markets and economic welfare. Transportation Research Part E: Logistics and Transportation Review, 33:181-195. 
PETRIN, A. \& TRAIN, K. E. (2002). Omitted product attributes in discrete choice models. Technical Report W9452, NBER Working Paper Series.

PFEIFFER, R. (2004). Voto-vista de conselheiro. processo administrativo n. 08012.000677/1999-70.

PHLIPS, L. (1987). Information and collusion. In HAY, D. \& VICKERS, J., editors, The Economics of Market Dominance. Basil Blackwell, Oxford.

Pinkse, J., Slade, M., \& Brett, C. (2002). Spatial price competition: A semiparametric approach. Econometrica, 70:1111-1155.

PRADO, L. (2004). Voto-vista de conselheiro. processo administrativo n. 08012.000677/1999-70.

RAGAZZO, C. E. J. (2006). O processo de flexibilização e as fusões e os acordos de cooperação no mercado de transporte aéreo de passageiros. Technical Report 32, Secretaria de Acompanhamento Econômico - SEAE.

RICHARD, O. (2003). Flight frequency and mergers in airline markets. International Journal of Industrial Organization, 21:907-922.

ROTEMBERG, J. \& SALONER, G. (1986). A supergame-theoretic model of price wars during booms. American Economic Review, 76:390-407.

SALGADO, L. H. (1997). O conceito de mercado relevante. Revista de Direito Econômico, 26.

SALOP, S. (1986). Practices that (credibly) facilitate oligopoly coordination. In STIGLITZ, J. \& MATHEWSON, F., editors, New Developments in the Analysis of Market Structure. MIT Press, Cambridge, MA.

SALVANES, K., STEEN, F., \& SOGARD, L. (2003). Collude, compete or both? deregulation in the norwegian airline industry. Journal of Transport Economics and Policy, 37.

SCALLOPE, L. (2004). Voto-vista de conselheiro. processo administrativo n. 08012.000677/1999-70.

SCALLOPE, L. \& FARINA, E. (2004). Acórdão. processo administrativo no. 08012.000677/1999-70.

SHAW, S. (1999). Airline Marketing and Management. Ashgate Publishing, Aldershot.

SLADE, M. (1986). Conjectures, firm characteristics, and market structure - an empirical assessment. International Journal of Industrial Organization, 4:347-369.

SLADE, M. (2004). Market power and joint dominance in UK brewing. Journal of Industrial Economics, 52:133-163.

STAIGER, D. \& STOCK, J. H. (1997). Instrumental variables regression with weak instruments. Econometrica, 65:557-86.

TAVARES, M. O. (1999). Transporte aéreo doméstico e a Lógica da desregulamentação. Technical Report 4, Secretaria de Acompanhamento Econômico - SEAE.

TRETHEWAY, M. (2004). Distortions of airline revenues: Why the network airline business model is broken. Journal of Air Transport Management, 10:3-14.

VISCUSI, W. K., M., V. J., \& E., H. J. (1995). Economics of Antitrust and Regulation. The MIT Press, Cambridge, MA.

WERDEN, G. (2000). Market delineation under the merger guidelines: Monopoly cases and alternative approaches. Review of Industrial Organization, 16:211-218. 
WHITE, L. J. (1999). Present at the beginning of a new era for antitrust: Reflections on 1982-1983.

WINDLE, R. \& DRESNER, M. (1999). Competitive responses to low cost carrier entry. Transportation Research, 35:59-75. part E.

\section{A. A TÉCNICA DE BOOTSTRAPPING}

O Bootstrap é um método desenvolvido originalmente por EFRON (1979) para se estimar a distribuição amostral de um estimador, por meio de reamostragem com reposição de elementos, da amostra original. A teoria de modelos baseados em amostragem para inferências estatísticas parte da hipótese de que os dados surgem como uma amostra de alguma distribuição de probabilidade conceitual $f$. Incertezas sobre as inferências podem ser medidas se for estimada $f$. A idéia fundamental do método do bootstrap é que se pode computar medidas de incerteza (média, intervalo de confiança, desvio-padrão, e outras) sobre inferências da distribuição de $f$ estimadas da amostra (BURNHAM, 2004).

Existem duas formas possíveis de se rodar o bootstrap: a paramétrica e a não-paramétrica. Quando existe um modelo matemático particular, com constantes ajustáveis ou parâmetros $\psi$ que determinam $f$, o modelo é chamado de paramétrico e os métodos estatísticos baseados nesse modelo são métodos paramétricos. Nesse caso, o parâmetro de interesse $\theta$ é componente ou função de $\psi$. Quando nenhum modelo matemático é usado, a análise estatística é não-paramétrica, e usa apenas o fato de que as variáveis aleatórias são independentes e identicamente distribuídas. No caso de se tratar de um modelo paramétrico, a análise não-paramétrica pode ser útil para indicar a robustez das extrações do mesmo (HAIR et alii, 1998).

Em geral, métodos de reamostragem são mais utilizados em aproximações não-paramétricas. Nesse caso, o procedimento consiste na geração de múltiplas amostras $\left(x^{*^{B}}\right)$, chamadas de reamostras ou pseudo-amostras, a partir de uma amostra inicial $(x)$ através de um processo aleatório e com reposição. Freqüentemente, a amostra é composta de $\mathrm{n}$ unidades independentes e isso basta para fazer um simples exemplo aleatório de tamanho n, com reposição, e obter uma amostra bootstrap.

O conjunto B das amostras bootstrap é uma proxy para um conjunto $B$ de amostras reais independentes de $f$ - na realidade, tem-se apenas uma amostra com dados reais. Propriedades esperadas da replicação da amostra original são inferidas a partir das amostras bootstrap, exatamente como inicialmente foi feito com a amostra real de dados. Do conjunto de resultados de amostra de tamanho B, pode-se medir as incertezas sobre a inferência da amostra para população. $\mathrm{O}$ bootstrap pode trabalhar bem para amostras de grandes tamanhos $(n)$, mas pode não ser confiável para pequenas $(n=5,10$ ou até 20). A distribuição bootstrap pode ser vista como aproximação altamente acurada da verdadeira distribuição da amostra do estimador (BURNHAM, 2004).

Em particular, tem-se como exemplo prático, o procedimento de bootstrap para estimar desviopadrões (EFRON e TIBSHIRANI, 1993):

1. Seleciona-se B amostras independentes de bootstrap $x^{* 1}, x^{* 2}, \ldots, x^{* B}$ cada uma consistindo de $n$ elementos gerados num processo aleatório e com reposição de $x$.

2. Estima-se o valor do parâmetro desejado correspondente a cada reamostra de bootstrap: $\hat{\theta}^{*}(b)=$ $s\left(x^{*^{b}}, b=1,2,3, \ldots, B\right.$, onde $\hat{\theta}^{*}$ é a réplica bootstrap de $\hat{\theta}$ e $\hat{\theta}$ é a estimativa do parâmetro de interesse, $\theta$.

3. Estimar o erro padrão $s e_{F}(\hat{\theta})$ pelo desvio-padrão das amostras das B réplicas:

$$
s \hat{e}_{B}=\left\{\sum_{b=1}^{B}\left[\hat{\theta}^{*}(b)-\hat{\theta}(.)\right]^{2} / B-1\right\}^{1 / 2},
$$

onde $s \hat{e}_{B}$ é o desvio-padrão das réplicas bootstrap de $s e_{F}(\hat{\theta})$ e $\hat{\theta}^{*}()=.\sum_{b=1}^{B} \hat{\theta}^{*}(b) / B$. 
Assim, na medida em que $B$ tende a infinito, o desvio-padrão estimado pelo bootstrap tende ao desvio-padrão da população. Pelo fato de que essa aproximação envolve a repetição do procedimento de análise dos dados originais com muitas réplicas do conjunto de dados, isso é às vezes chamado de método intensivo-computacional (DAVISON e HINKLEY, 1997).

Como enfatizado, o algoritmo de bootstrap acima descrito pode ser utilizado também como mecanismo de correção de desvio-padrão em modelos que empregam como regressor uma variável estimada. Isso se aplica ao procedimento em duas etapas aqui efetuado, nos quais o desvio-padrão dos parâmetros da segunda etapa deve ser ajustado para refletir o fato de que sua matriz de covariância contém ruído induzido pelas estimativas da primeira etapa (KARACA-MANDIC e TRAIN, 2003). Assim, a equação da segunda etapa pode ser estimada normalmente, mas os resultados finais reportarão uma matriz de variância-covariância ajustada a partir de valores resultantes de bootstrap aplicado a variáveis estimadas na primeira equação, e presentes como regressores na segunda equação.

\section{B. LUCRATIVIDADE NO MERCADO (DADOS CONTÁBEIS)}

Figura 1 - Evolução da Taxa de Lucratividade (\%) na Ponte Aérea Rio de Janeiro - São Paulo (Fonte: Anuário DAC - Vol II)

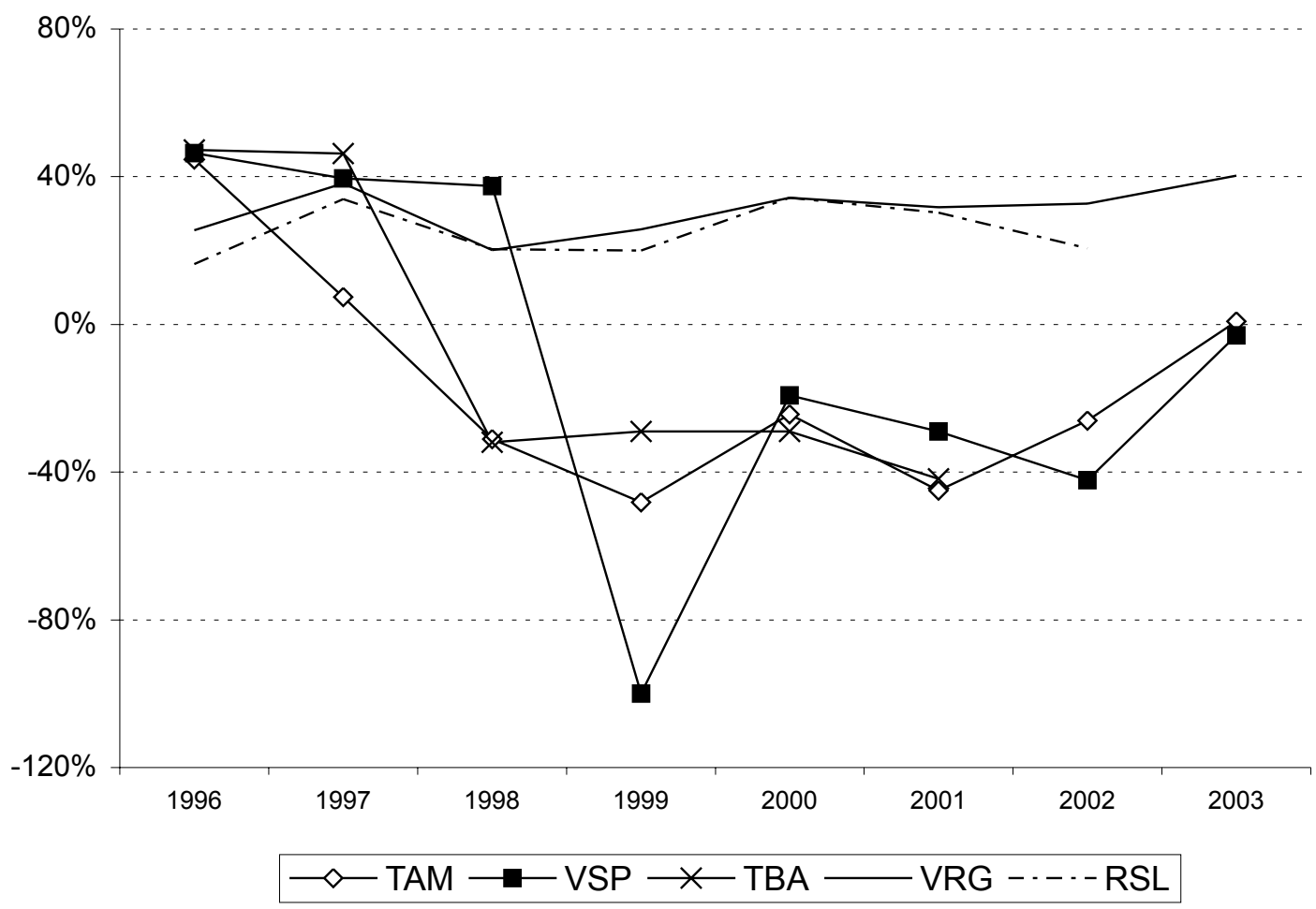

